University of South Florida

DIGITAL COMMONS

Digital Commons @ University of

@ UNIVERSITY OF SOUTH FLORIDA

South Florida

World Languages Faculty Publications

World Languages

2016

\title{
Portuguese Studies on Medieval Illuminated Manuscripts
}

David Arbesu

University of South Florida, arbesu@usf.edu

Follow this and additional works at: https://digitalcommons.usf.edu/wle_facpub

Part of the Arts and Humanities Commons

\section{Scholar Commons Citation}

Arbesu, David, "Portuguese Studies on Medieval Illuminated Manuscripts" (2016). World Languages

Faculty Publications. 15.

https://digitalcommons.usf.edu/wle_facpub/15

This Book Review is brought to you for free and open access by the World Languages at Digital Commons @ University of South Florida. It has been accepted for inclusion in World Languages Faculty Publications by an authorized administrator of Digital Commons @ University of South Florida. For more information, please contact digitalcommons@usf.edu. 
ANUARIO DE Estudios MEDIEVALES

46/1, enero-junio de 2016, pp. 493-541

ISSN 0066-5061

\section{RESEÑAS}

Glaire D. ANDERSON, The islamic villa in early medieval Iberia. Architectura and court cultura in Umayyad Córdoba, Surrey, Ashgate, 2013, 225 pp. ISBN 978-1-4094-4943-0.

Desde su perspectiva de historiadora del arte, con esta obra la autora persigue el objetivo explícito de inserir las almunias cordobesas entre las residencias elitistas que suponen las villas en occidente, contribuyendo a llenar el largo vacío que aquí separa las villas de la aristocracia romana de aquellas otras del Renacimiento, según la vieja propuesta de Jacob Burckhardt. Para ello cuenta con abundantes referentes selectos de otros tiempos y espacios no occidentales, como los alcázares omeyas del desierto sirio, si bien centra su estudio en las almunias periurbanas cordobesas entre los siglos VIII-X, analizando también su dimensión social como expresión de patronazgo. Según su hipótesis, tales almunias derivarían de un modelo de residencia aristocrática de antiguas raíces que aquí podría haber sobrevivido, más o menos intacto, hasta la llegada del Islam.

Como primer antecedente refiere el alcázar o palacio de Rusāfa, adquirido por el emir Abd al-Rahmān y cuyo nombre evoca la fundación homónima de su abuelo en Siria, si bien fue un jefe bereber partícipe en la invasión quien emprendió su construcción y otras obras en su entorno. Es hacia mediados del siglo IX cuando las almunias prueban su carácter público, adscritas a gobernantes, concubinas o sirvientes, conociendo su edad de oro durante el califato, en un contexto de renovación cortesana y en manos de las élites dependientes, como ocurre con el tesorero Durrī al-Saghïr, finalmente depuesto y ejecutado.

Sus formas se ejemplifican mediante el caso mejor conocido, el de alRummāniyya de tiempos de Durrī, un gran recinto monumental donde las estructuras residenciales, de representación y de servicios presiden un amplio espacio de cultivo. Aquí destaca la posición central que ocupa un doble vestíbulo situado frente a la alberca monumental y los jardines, contando con un referente similar en la residencia califal de Madīnat al-Zahrā', disposición que descartan los complejos cortesanos posteriores. Vestíbulos transversales semejantes permiten a la autora sugerir cierto tipo de villa regional porticada cuyos paralelos lejanos pudieran encontrarse en complejos bajoimperiales hispánicos o norteafricanos, si bien no dispone de otro referente más próximo que el caso valenciano de Pla de Nadal, que considera de fines de época visigoda. Junto con otros hallazgos del entorno cordobés, al-Rummāniyya también proporciona abundante ornamento arquitectónico, cuya escultura representa motivos vegetales, fauna y alguna figura humana, equiparables a las producciones del taller califal de marfiles, que de hecho reproducen el ambiente de las almunias.

Descritas por la poesía andalusí como jardines placenteros, repletos de fragancias, sus tierras se dedicarían principalmente al cultivo de olivos, viñas e higueras a pequeña escala, donde el agua resulta esencial, requiriendo obras específicas de captación o de construcción de acequias y acueductos. En cualquier caso, almunia 
sería entonces un término específico que solo recibirían estas residencias cordobesas, distinguiéndolas de otras explotaciones abiertas como las alquerías con sus campos extensos. Desde un principio fueron también receptoras de nuevas especies vegetales, precediendo los jardines botánicos de tiempos taifas, si bien se remarca que en sus huertos predominaría una selección de plantas con fines culinarios, cosméticos o farmacéuticos, siendo espacios destinados a la vida social de las élites o lugares de retiro.

Ellas representan la refinada imagen política y religiosa que ofrece el califato, donde se hospedan séquitos y embajadas o, incluso, se ejecuta enemigos. También son escenario de fiestas y celebraciones, cuando se congregan multitudes y se consume o regala a gran escala, así como se acogen cortejos ceremoniales o procesiones cívicas. Mientras la soberanía omeya se proyecta mediante todo tipo de objetos, también las almunias proclaman y legitiman su buen gobierno, simbolizando un paisaje rural bien cultivado según el orden natural y social, siguiendo los ciclos agrícolas y el calendario de la administración. Las almunias califales también son al cabo referentes de los ideales aristocráticos refinados y del buen gusto, con notable influencia ulterior, imbricadas como están en una amplia constelación de palacios.

Cabe concluir que la autora construye una detallada imagen de la vida social y del ambiente de las almunias cordobesas durante el califato, adecuadamente comparada con sus paralelos orientales y con sus precedentes o epígonos inmediatos. Cabe agradecer también su cuidada edición, profusamente ilustrada y que acompaña una selección de textos árabes, resultando una aportación recomendable tanto para estudiantes como expertos. No obstante, el lector dudará si realmente se consigue integrar estas almunias en una tradición continua de villas occidentales, como se insiste. Si bien los paralelos orientales aducidos son claros, tanto a nivel formal como sociológico, en cambio cuesta creer que las realizaciones cordobesas procedan directamente de aquellas, puesto que se desconocen eslabones ciertos que unan ambas tradiciones. Desde la arqueología, cabe observar que hoy cada vez más voces se pronuncian a favor de una temprana desaparición del modelo de villa bajo imperial en Hispania, que no superaría el siglo VI, mientras que Luís Caballero retrasa la construcción de Pla de Nadal hasta comienzos del emirato, cargado de razones.

Rico en monumentos antiguos, el paisaje que conoció la conquista del 711 fue metódicamente ocupado desde un principio, si bien hubo que esperar hasta el año 719 para aplicar las órdenes califales de reparto. Entonces se asignó al naciente Estado una quinta parte de las tierras obtenidas, atribuyéndole cientos de explotaciones que reciben las denominaciones específicas de palatium, qașr o balāt por todo al-Andalus, como venimos observando. Son cuestiones que remiten de nuevo sobre oriente y la misma expansión musulmana, tanto en Siria como a partir de aquí, entre precoces iniciativas edilicias que incorporan múltiples tradiciones. En Córdoba, tras la llegada del Emigrado el devenir histórico hizo el resto.

RAMON MARTí

Universtitat Autònoma de Barcelona 
Patrice BecK, Philippe BERNARd, Laurent FELler (dirs.), Rémunérer le travail au Moyen Âge. Pour une histoire sociale du salariat, Paris, Picard, 2014, 527 pp. ISBN 978-2-7084-0971-2.

Reúne la presente publicación un elevado número de trabajos, agrupados en cuatro partes, que abordan desde múltiples puntos de vista el problema historiográfico de la remuneración del trabajo en la Europa occidental durante los siglos medievales. Se trata de trabajos fruto de varios seminarios celebrados en Francia a lo largo de tres años, en los que participaron especialistas de muy diversos países del occidente europeo, coordinados por los profesores Patrice Beck, Philippe Bernardi y Laurent Feller. Abordan un problema fundamental que desde finales del siglo XIX ha suscitado preferentemente el interés de los historiadores de la economía, pero que también debería ocupar un lugar privilegiado en la escala de prioridades de la historia social. Y es precisamente desde la perspectiva de esta última desde la que se aborda dicho problema en los trabajos reunidos en este libro, que no se ocupan tanto de la identificación de los factores económicos que explicarían la evolución a corto, medio o largo plazo de los salarios en la Europa medieval, o del análisis del papel que la remuneración del factor trabajo desempeñaba en la economía de la época, sino que más bien tratan de profundizar en el estudio de las relaciones existentes entre la forma en que se llevaba a efecto dicha remuneración y las estructuras sociopolíticas.

Tanto el libro en su conjunto, como las cuatro partes en que se encuentra dividido, se inician con sus correspondientes introducciones, que informan al lector sobre las cuestiones concretas a las que se trata de dar respuesta en los estudios de casos concretos que siguen a continuación, cuyos resultados son en parte adelantados mediante referencias puntuales en apoyo de la argumentación. A su vez, el libro se cierra con un texto a cargo de M. Bourin, en el que esta autora ofrece un detallado balance global de las aportaciones de los trabajos reunidos, y en el que desgrana múltiples noticias relativas a cuestiones concretas abordadas en ellos. De este modo se consigue facilitar la asimilación de las principales ideas que autores y coordinadores han tratado de transmitir, resultando una obra de notable eficacia pedagógica, aunque en ocasiones pueda resultar reiterativa.

En la primera parte se ofrece un balance de las aportaciones de la historiografía de diversos países europeos al estudio de la remuneración del trabajo durante el período medieval, desde las décadas finales del siglo XIX, cuando los trabajos pioneros de Thorold Rogers en Inglaterra y de Georges d'Avenel en Francia marcaron el inicio de las investigaciones sobre esta materia, hasta el momento presente. En concreto, los países tomados en consideración son Italia, España, Portugal, Alemania e Inglaterra, corriendo a cargo de los siguientes autores el informar sobre cada uno de ellos: G. Pinto, de la universidad de Florencia; P. Benito, de la de Lleida; A. Sousa Melo, de la de Braga; N. Bulst, de la de Bielefeld, y Ph. Schofield, de la de Gales. Llama la atención que no se incluye ningún trabajo centrado en el caso de Francia, si bien esta ausencia queda compensada con la inclusión de dos colaboraciones de carácter también historiográfico, donde dos autores franceses informan sobre la forma en que se ha abordado la problemática de la remuneración del trabajo por parte de los economistas, en el caso de J. Gautié, y de los estudiosos del derecho, en el de R. Carvais. En conjunto, los trabajos reunidos en esta primera parte nos permiten 
conocer interesantes peculiaridades de las tradiciones historiográficas de cada país, que explican que en esta materia en unos se haya prestado más atención a unos aspectos, y en otros a otros. Así, por ejemplo, se nos informa sobre cómo en Alemania ha primado la edición de fuentes originales, en Inglaterra la elaboración de series susceptibles de tratamiento estadístico, y en Italia la aproximación jurídica e institucional. No obstante también se pone de manifiesto cómo en algunos países la llegada de investigadores extranjeros pudo resultar determinante para abrir nuevos caminos, que nada deben a las tradiciones nacionales, como ilustraría, por ejemplo, el caso de la actividad pionera del norteamericano Hamilton en España. Del mismo modo, en este balance también se pone de manifiesto el carácter determinante que para el desarrollo de unas u otras líneas de investigación ha tenido la tipología de la documentación conservada, que presenta características muy diferentes de unos lugares a otros.

La segunda parte agrupa los trabajos que analizan la problemática de la remuneración del trabajo desde el punto de vista semántico, abordando el estudio del vocabulario utilizado en los documentos y otro tipo de fuentes para referirse a la misma, en la mayor parte de los casos durante los últimos siglos del Medievo, con la excepción del trabajo de Laurent Feller, que, por el contrario, se centra en el período altomedieval. La comparación entre los resultados de este trabajo y los de los restantes permite advertir una clara evolución en el transcurso del período medieval desde una situación inicial marcada por la omnipresencia de las relaciones feudales y de dependencia, que explica la casi total ausencia del concepto de salario en las fuentes altomedievales, hacia otra en la que van adquiriendo progresivo desarrollo las relaciones contractuales, y comienza a individualizarse una relación salarial propiamente dicha, con muy diversos matices, que explican la abundancia y notable diversidad de términos utilizados en las fuentes, tanto en lengua latina como en vernácula, para hacer referencia a la remuneración salarial. De esta diversidad dan cumplida cuenta los trabajos que contienen estudios de caso, que se centran en ámbitos concretos, más o menos extensos, de la Europa Occidental. En concreto Neithard Bulst dedica su atención al dilatado ámbito alemán, el único de lengua germánica tomado en consideración en esta ocasión, pues no se incluye ningún trabajo sobre tierras de lengua anglosajona. Arnaldo Sousa Melo estudia el vocabulario empleado en las fuentes normativas portuguesas. Pere Benito analiza los más antiguos contratos de aparcería que se conservan en Cataluña, procedentes de los siglos XI al XIII, desde la perspectiva de la utilización que en ellos se hace del término latino conductum, para contribuir a la clarificación del problema de la situación de la mano de obra asalariada en el sector agrario en este temprano período. Francine Michaud, por su parte, centra su atención en los contratos de aprendizaje y de empleo que se conservan en los protocolos notariales de Marsella de los siglos XIII y XIV, para dar cuenta de la evolución del vocabulario empleado para referirse a la remuneración del trabajo en esta ciudad provenzal, y Philippe Bernardi, basándose en este mismo tipo de documentación, hace lo propio para un período posterior, el siglo XV y la primera mitad del siglo XVI, en este caso en el conjunto de la región de Provenza. Fabienne Couvel y Matthieu Leguil analizan esta misma problemática en la región de Borgoña en los siglos XIV y XV, mientras que, por fin, el espacio de lengua italiana es objeto de estudio en un trabajo a cargo de Giuliano Pinto y Franco Franceschi en el que analizan el vocabulario empleado en la Toscana entre los siglos XIII y XV. 
La tercera parte aborda la cuestión de la caracterización de las modalidades que adoptó la remuneración del trabajo, que, según se demuestra en los cinco estudios de caso que en ella se reúnen, alcanzaron una enorme diversidad. Utilizando fuentes documentales bastante diferentes de unos casos a otros, los autores centran su atención en espacios relativamente restringidos, que representan a ámbitos muy diversos de la Europa occidental. En concreto, S. Victor estudia el caso concreto de la ciudad de Gerona, centrando su atención en la mano de obra asalariada del sector de la construcción, que trabajó en edificios eclesiásticos y obras públicas como la muralla. F. Riviére, desde la perspectiva que ofrecen las fuentes normativas que regulaban el ejercicio de las profesiones, centra su análisis en dos pequeñas ciudades de Normandía, Lisieux y Gisers, en el período que va de 1430 a 1540. A. Sousa Melo nos informa sobre las modalidades de remuneración del trabajo en el reino de Portugal del siglo XV. M. Scherman, basándose en la información proporcionada por documentación fiscal que contiene las declaraciones de bienes que realizaban los vecinos para el cálculo de lo que les correspondía pagar en el impuesto directo del estimo, estudia el caso de la ciudad bajo dominio veneciano de Treviso durante el siglo XV, aportando informaciones de gran interés para conocer la situación de los trabajadores en los ámbitos domésticos. Y, por fin, P. Beck informa sobre las formas de remuneración de la mano de obra que trabajó a principios del siglo XV en tareas de reparación de los lagares del duque de Borgoña en las proximidades de Dijon. Tan heterogénea muestra de estudios de caso permite constatar que las modalidades a las que se recurrió para remunerar el trabajo fueron extraordinariamente diversas, pues podemos comprobar gracias a múltiples referencias concretas cómo hubo salarios por jornada trabajada, o a destajo, entregados en dinero o en especie, $y$, sobre todo, se añadieron a ellos otros muchos complementos de muy diversas características que diversificaron hasta el extremo las situaciones constatables.

La cuarta parte, por fin, reúne nueve contribuciones que buscan profundizar en la identificación de los criterios que se aplicaron en las sociedades europeas bajomedievales para evaluar la remuneración que se había de conceder al trabajo, es decir para fijar las diferencias de nivel entre los distintos salarios abonados. Su objetivo principal consiste, por consiguiente, en clarificar la cuestión de la medición del valor del trabajo, considerado como categoría en sí misma, y no como simple medio para acceder al conocimiento de los niveles de vida mediante la puesta en relación de la evolución de los salarios con la de los precios.

Al igual que en la parte tercera, los estudios de caso reunidos ponen de manifiesto que los criterios aplicados estuvieron extraordinariamente diversificados, pues se tuvieron en cuenta, según los casos, múltiples variables relacionadas con el tiempo que duraba la prestación del trabajo, las jerarquías sociales y profesionales preexistentes, el nivel de competencia, habilidades, fuerza física o cualificación técnica del trabajador, o la propia incidencia de la situación del mercado de trabajo. Pero, por otro lado, ni siquiera la toma en consideración de esta multiplicidad de criterios permite explicar siempre de forma satisfactoria las diferencias de salarios abonados a los distintos trabajadores que se constatan en las fuentes, como bien se pone de manifiesto con ejemplos concretos en varias contribuciones.

Por lo demás, estos nueve estudios de la cuarta parte son muy heterogéneos, pues se mezclan en ellos visiones de conjunto sobre amplios espacios, con análisis 
en profundidad de casos muy concretos. Así, N. Bulst nos ofrece un panorama global sobre la problemática de la evaluación de los salarios en el extenso espacio alemán, mientras que G. Pinto también presta atención a un extenso territorio, el de Italia, aunque restringe su estudio al sector de la construcción entre los siglos XIII y XV. Roser Salicrú i Lluch, por su parte, se ocupa del principado de Cataluña aunque no desde una perspectiva general, sino centrando su atención en dos sectores que no han solido ser muy tenidos en cuenta en los estudios sobre la remuneración del trabajo en el mundo medieval, los de la construcción naval y la navegación marítima. Se trata de dos sectores que ofrecen notables peculiaridades, satisfactoriamente puestas de manifiesto por la autora, que además aporta informaciones inéditas de interés, entre las que destacaríamos las relativas a la presencia de esclavos entre los trabajadores asalariados, los cuales se demuestra que recibían una remuneración por su trabajo muy semejante a la percibida por los trabajadores de condición libre de su misma cualificación.

Más centrados en el análisis en profundidad de casos concretos están el resto de los trabajos. En primer lugar tenemos dos estudios basados en la utilización de documentación pontificia: el de E. Anheim y V. Theis centrado en la identificación de los criterios de remuneración del trabajo en el sector de la construcción en la Curia pontificia de Avignon durante el siglo XIV, y el de A. Jamme sobre la retribución del servicio de armas por el Papado en los territorios italianos en este mismo siglo. F. Michaud, por su parte, circunscribe su análisis al ámbito concreto de la ciudad de Marsella, utilizando un conjunto documental de algo más de 800 contratos de empleo localizados en sus protocolos notariales de la segunda mitad del siglo XIII y del siglo XIV. Éstos le permiten profundizar en el estudio del funcionamiento efectivo del mercado del trabajo en la realidad cotidiana, y, entre otras muchas cosas, advertir las importantes consecuencias que el declive demográfico que siguió a la Peste Negra tuvo en este terreno. Por fin, otros dos estudios referidos a casos muy concretos son los de F. Franceschi, que se ocupa de los criterios para la fijación de las diferencias de salario en la manufactura de paños de lana de la ciudad de Florencia durante los siglos XIV y XV, y el de D. Boisseuil y P. Chareille que aborda el análisis de esta misma problemática en una mina de alumbre, la de Monterrotondo Marittimo, en Toscana, a fines del Medievo.

En esta cuarta parte se incluye por fin una contribución a cargo de R. Carvais, historiador del derecho, que ciertamente comparte con las demás el objetivo de contribuir a clarificar la cuestión de la identificación de los criterios de evaluación del trabajo en el pasado, prestando atención en esta ocasión a los que se manejan en documentación judicial relativa a la mano de obra del sector de la construcción en Francia. Pero presenta la peculiaridad de que se trata de documentación de los siglos XVII y XVIII, es decir muy posterior al período medieval en el que se centran el resto de contribuciones que abordan esta problemática.

De una obra de contenido tan heterogéneo como la presente resulta difícil ofrecer una valoración global, aunque entendemos que ha de ser elogiosa por muy diversas razones. En primer lugar, consideramos que el libro es el resultado de una buena planificación, gracias a la cual, aunque se detecten los inevitables desequilibrios y lagunas, el cuadro final que se nos ofrece resulta equilibrado, con muy pocos elementos manifiestamente discordantes. En segundo lugar, resulta digno de aplauso el esfuerzo realizado por diversificar las perspectivas de análisis de una cuestión que 
la historiografía clásica tendía a abordar de forma prácticamente exclusiva desde la perspectiva de la historia económica, con una metodología, además, que concedía prioridad a la vertiente estadística. Por este motivo había sido hasta ahora la documentación relativa al sector de la construcción la más utilizada para abordar el estudio de la remuneración del trabajo hasta el fin del Antiguo Régimen. En este libro, ciertamente también siguen teniendo un peso importante los trabajos que utilizan como principal fuente de información este tipo de documentación, pero como aspecto novedoso de varios de ellos cabe destacar la incorporación al campo de estudio de otros muchos sectores, hasta ahora descuidados, desde el de la navegación marítima hasta el de los servicios militares en los ejércitos mercenarios, pasando por el de la minería. Al leer este libro nuestros horizontes se amplían de forma considerable, por múltiples razones que tienen mucho que ver con los criterios seguidos por los coordinadores para seleccionar los autores de las contribuciones, que representan a un amplio abanico de países y de orientaciones metodológicas. Por todo ello recomendamos encarecidamente su lectura.

Máximo Diago HeRnando Instituto de Historia, CSIC. Madrid

Monique Bourin, John Drendel, François Menant (eds.), Les disettes dans la conjoncture de 1300 en Méditerranée occidentale, Rome, École Française de Rome, 2011, 438 pp. (Collection de l'École Française de Rome; 450). ISBN 978-27283-0903-0.

Este volumen contiene las actas de un coloquio celebrado en Roma en febrero del 2004 bajo los auspicios de l'École Française de Rome. Los participantes fueron invitados a examinar las crisis de subsistencia en los países del Mediterráneo occidental desde la perspectiva de la coyuntura del 1300. De hecho, se trató de ver si encajaba en el occidente mediterráneo el paradigma construido desde 15 años atrás por historiadores anglosajones que, a través del estudio del desarrollo comercial, cuestionan la existencia de la crisis del siglo XIV. Las convergencias entre los participantes en el coloquio dominan sobre las divergencias, y, de hecho, las actas no recogen debate alguno. Sin pretensiones, intentaremos suplir la ausencia, no sin antes subrayar que estamos ante una obra importante.

El debate imaginado podría empezar por el estudio introductorio de Monique Bourin y François Menant, que alertan sobre el paradigma neomaltusiano tradicional, según el cual las hambres de principios del siglo XIV serían un indicador del cambio de coyuntura, efecto de un mundo sobrepoblado, donde la producción no alcanzaba a cubrir las necesidades de la población. Su crítica a la interpretación maltusiana incluye, como es de rigor, la necesidad de no olvidar la desigual distribución de la riqueza. Totalmente de acuerdo, pero sucede que las crisis de subsistencias son crisis cortas que no se producen todos los años, un hecho que debería obligar a reflexionar e introducir con no menor fuerza en el análisis el factor climático, un factor al que, con excepciones (A. Riera, J. Drendel, C. Reglero), los autores del volumen no otorgan la importancia que merece. En cambio, todos subrayan el papel determinante 
del mercado, un papel que les sirve tanto para explicar las crisis como para resaltar el dinamismo de las sociedades del 1300. Aunque el punto de vista de A. Furió es más sutil: las crisis de subsistencia del siglo XIV no serían tales sino desajustes en el crecimiento y en la integración entre centros de producción y de consumo.

Con excepciones (P. Benito, A. Riera), los autores parecen prisioneros de la cronología adoptada (de hecho: 1250-1347), y no debería olvidarse que las crisis de subsistencia se han producido siempre, en todas las épocas. Es más, fueron muchas e importantes durante el crecimiento medieval. Y hoy es muy difícil diferenciar entre las de esta época y las de 1250-1347, en cuanto a gravedad, extensión y frecuencia. En suma, las hambres, tal como se examinan en el libro, no nos parece que sirvan para enjuiciar la coyuntura del 1300.

Quizá, para calibrar la importancia de las crisis del 1300, pudieran servir las migraciones de hambre que parecen especialmente importantes en este siglo, como inicio del pauperismo: una pobreza social tan extendida y crónica que los recursos tradicionalmente adoptados por la sociedad ya no eran suficientes y resultaba necesario inventar nuevas soluciones. Es posible que para situar las hambres del 1300 en un contexto de crecimiento o de decrecimiento pudiera servir también la apreciación de la capacidad de recuperación de la sociedad, algo que requeriría echar mano de la historia comparada. Nuestra impresión es que la sociedad del crecimiento medieval cicatrizaba con más o menos rapidez las heridas de las hambrunas y reemprendía el crecimiento, mientras que la sociedad del decrecimiento no las cicatrizaba o lo hacía más tarde y con mayor dificultad, aunque esta imagen puede que esté distorsionada por el efecto de las epidemias sobre el volumen de población, y seguro que no es válida en todas partes.

En cualquier caso, la relación entre producción y población, a que antes nos referíamos, es un tema sobre el que los participantes en el coloquio pasan de puntillas. No todos, bien es cierto: A. Furió acepta el paradigma para negar su aplicación a la España del 1300, con el argumento de la lucha contra el Islam, que habría puesto en manos de la sociedad feudal una inmensidad de tierras sobre las que extender la empresa colonizadora y sostener largamente el crecimiento, algo (se deduce) que no se habría producido en otras partes de Europa. Pero Furió sabe que, a pesar de este crecimiento, en la Corona de Aragón, en general, y en el reino de Valencia, en particular, no dejó de haber crisis de subsistencias. Frente a esta aparente paradoja su respuesta es que no se trata de un cambio de coyuntura, y raramente del resultado de crisis agrarias, sino más bien de accidentes del crecimiento. También Gilbert Larguier, hablando del Languedoc, se enfrenta al paradigma maltusiano para dudar de su validez con el argumento de la continuidad de las crisis de subsistencia después de la Peste Negra, cuando se supone que había descendido el volumen de población. Cuestionado el paradigma maltusiano (aunque G. Pinto habla de desequilibrio entre producción interna y necesidades de consumo), el mercado pasa a ocupar su lugar como causa de fondo de las crisis. Es la impresión que se deduce de la lectura del conjunto de las ponencias.

Sin negar los efectos que los cambios en el mercado (flujos y precios) tuvieron sobre el aprovisionamiento de las poblaciones urbanas, es conveniente recordar que las preindustriales fueron sociedades de riesgo, donde amplios sectores de población dependían de la regularidad de las cosechas. Cuando el clima no era propicio, el cereal escaseaba y subía de precio, circunstancia que la especulación agravaba. 
Y cuando esto se producía la crisis de subsistencias estaba asegurada y, con ella, el incremento de la mortalidad. En resumen, el binomio población/producción no es ajeno a la problemática, y el concepto de sobrepoblamiento no debería escandalizar, sólo hace falta adjetivarlo de relativo y explicar que tiene efectos mortales cuando actúa en sociedades desiguales como la del 1300.

Por otra parte, los autores concentran la mirada sobre el mundo urbano en detrimento del rural, donde vivía la mayor parte de la población, y olvidan la estratificación campesina: la capa, probablemente mayoritaria el 1300, de campesinos de poca tierra que vivían en el límite de la subsistencia, orientaban su producción al autoconsumo y al pago de deudas, rentas e impuestos, frecuentaban poco el mercado y vendían fuerza de trabajo para equilibrar sus economías. Eran los más expuestos a los fracasos de las cosechas, los que alimentan las migraciones de hambre en toda Europa.

Empezaba entonces a desarrollarse el mercado que podríamos llamar internacional basado en el transporte a larga distancia (P. Benito). Dato importante. Los mercaderes que lo gestionaban, ponían en comunicación las regiones productivas y los grandes centros de consumo, y, como cabe suponer, orientaban la oferta hacia la demanda solvente, manipulaban en lo posible los precios a su favor y ellos y los consumidores no debían ser ajenos ni permanecer indiferentes a los rumores e informaciones sobre producción y precios. El capitalismo afloraba. Nada que criticar, sólo añadir. Si tomamos las series del diezmo en Andalucía, en la baja Edad Media, publicadas hace años por M.Á. Ladero y M. González, y las comparamos con los precios en Castilla la Vieja en la misma época, y repasamos la lista de años malos en la Navarra de M. Berthe y P. Monteano (aunque internamente diferenciada por la geografía y el clima: C. Laliena), observamos correspondencias, que en muchos casos pueden hacerse extensivas a la Cataluña de la misma época, según las series de producción y precios de C. Argilés en su tesis sobre Lérida. Es difícil imaginar que flujos mercantiles, oleadas de rumores y maniobras especulativas causaran carestías y hambres al unísono en toda la Península. Y si comparamos estos datos con los del Norte de los Pirineos, la Provenza e Italia, y observamos también aquí crisis de subsistencia más o menos graves esos mismos años, alimentaremos la sospecha de que la única causa posible de unas crisis tan generalizadas en el 1300 era la conjunción entre las alteraciones climáticas causantes de malas cosechas (algo que los propios cronistas confirman) y las incapacidades del sistema social.

Podemos menospreciar la historia comparada entre países y decir que son meras coincidencias, que los testimonios de los cronistas no son objetivos y que el paradigma de las crisis de tipo antiguo, tal como las estudiaron E. Labrousse. P. Vilar, J. Nadal o G. Anes, debe revisarse dando más protagonismo y autonomía al mercado. Admitámoslo, pero guardémonos de pensar que el mercado del 1300 es comparable al de los países contemporáneos del Tercer Mundo y que el análisis de Amartya Sen es aplicable a la Europa de seiscientos años atrás. Entonces, en el 1300, el capitalismo mercantil empezaba a desarrollarse en el seno del feudalismo, un sistema donde los que más abastecían el mercado no eran productores sino perceptores de rentas, nobles y eclesiásticos que no actuaban con la mentalidad del capitalista buscador del máximo beneficio y para ello dispuesto a asumir el riesgo. Los gobernantes tampoco actuaban movidos por una lógica capitalista sino feudal, lo que entrañaba un 
paternalismo que en momentos de crisis sacrificaba las ganancias de los más poderosos en aras de la paz social, y que, en contra de los intereses de los mercaderes y a favor de los consumidores locales, limitaba la libre circulación del cereal e incluso prohibía su salida no sólo del reino sino muchas veces de los términos de la propia ciudad, movilizaba los stocks privados y, si se estimaba necesario, tasaba los precios. Sobre estas medidas, que las masas populares reclamaban, a menudo había conflicto entre poderes locales, regionales y suprarregionales, lo que también es propio de un capitalismo en construcción.

Los participantes en el coloquio no abundaron en esta perspectiva, pero aportaron información que permite profundizar en las reacciones de los poderes públicos, sobre todo urbanos (Ch. de La Roncière, A. Riera, P. Savy, G. Pinto), ante las crisis, unas reacciones que en todas partes fueron las mismas y que se comprenden mejor desde la óptica del pensamiento y la mentalidad feudal que de la capitalista: G. Pinto las justifica por el temor a la agitación social.

Para concluir: en el momento actual en que el mundo está muy preocupado por el cambio climático, es deseable que los estudiosos de las crisis de subsistencia en la Edad Media resitúen el clima en el centro del análisis. Expertos en historia del clima (E. Le Roy Ladurie, B. Fagan) ya hace tiempo que fecharon en 1300-1850 una fase climática, la Pequeña Edad de Hielo, no propicia para las buenas cosechas. Pero son historiadores de la Edad Moderna (M. Lachiver, G. Parker) y de la Contemporánea (M. Davis) los que han escrito obras que mejor permiten comprender los efectos dramáticos de las alteraciones climáticas y las consiguientes malas cosechas sobre las sociedades históricas, unos efectos que las desigualdades, las dominaciones y las explotaciones agravaron. Y en el presente sólo hace falta recordar que los expertos de la FAO dan a menudo la voz de alarma sobre la falta de lluvia y la sequía en los países del Sahel, de lo que deducen que habrá malas cosechas, carestía y hambre, y que harán falta donaciones y ayudas para paliar la más que previsible crisis...

JOSEP M. SALRACH

Universitat Pompeu Fabra

Janet Burton, Karen STÖBER (eds.), Women in the Medieval Monastic World, Turnhout, Brepols, 2015, 377 pp. (Medieval Monastic Studies; 1). ISBN 9782-503-55308-5.

La recuperació del paper de les dones en la Història ha estat una constant en la historiografia dels darrers anys, el que ha donat lloc a la denominada "història de la dona o de gènere". Es tracta d'un exercici necessari que pretén estudiar els fenòmens històrics en l'àmbit femení, no només en personatges destacats, sinó també en el conjunt anònim -usant la microhistòria- $i$ donar veu a aquelles que han estat tradicionalment silenciades per la historiografia i pels rols socials. A tal efecte, els estudis monàstics no resten al marge de les tendències actuals, com demostra l'obra que es presenta.

Women in the Medieval Monastic World aporta noves perspectives sobre la història de la dona en el monacat medieval. Editat per Janet Burton i Karen Stöber 
-profundes coneixedores del món monàstic cistercenc-, recull els estudis que es presentaren a les II Jornades d'Història del Monestir de les Avellanes, que, titulades El monacat femení a l'Europa Medieval, tingueren lloc el juliol de 2011 en el monestir d'Os de Balaguer. Les quinze ponències que s'hi exposaren per sengles especialistes han estat degudament elaborades i revisades per formar una obra col·lectiva que esdevindrà una referència per als investigadors que s'endinsin en la història dels ordes femenins. En aquest tipus de llibres és inevitable que cada capítol es dediqui a una qüestió específica, a una cronologia determinada i a una geografia concreta, però aquesta fragmentació suposa que el volum recorri un ampli espectre territorial durant un vast període i que abordi des de diverses perspectives la qüestió central: el monacat femení. Tot plegat conforma un llibre amb una riquesa de mires i aproximacions que el converteixen en un excel·lent aparador de les investigacions en curs i en obertura de noves possibilitats. A més, la disposició dels capítols, una mica diferent a la de les ponències, el dota de coherència d'acord amb una estructura temàtica.

Així doncs, els tres primers capítols tracten sobre la identitat del monacat femení i la seva relació amb l'aristocràcia. G. Cavero estudia els monestirs dels regnes ibèrics cristians durant els segles XI i XII, i els vincula tant als ordes monàstics com als principals llinatges, fundadors de claustres i proveïdors de monges $\mathrm{i}$ abadesses. Per la seva banda, G. Cariboni se centra en el cas de les cistercenques del nord d'Itàlia, determinant com es va bastir la identitat de l'orde del Cister a partir de l'edificació o la incorporació de monestirs femenins, amb la presència d'una variada casuística en el seu interior. Finalment, M. Gaillard s'aproxima al monacat femení de la França septentrional entre el segles VII i la reforma carolíngia del IX, analitzant alguns dels monestirs en un difícil període escàs en fonts.

B. Golding i J. Burton són els autors dels dos capítols següents, que conformen un bloc dedicat a la relació entre les monges i l'autoritat masculina. L'Edat Mitjana fou una època controlada pels barons, i les dones, tot i l'important rol que podien arribar a assumir, sovint restaven sotmeses a un poder masculí. En el cas de les monges, és destacable la submissió al bisbe, objecte aquesta del capítol de Golding. També Burton estudia el domini episcopal sobre les cistercenques, a més de la subjecció de les monges a la jerarquia de l'orde dels monjos blancs. El marc geogràfic d'ambdós autors són els territoris d'Anglaterra i Gal·les, però obtenen unes conclusions que es poden mirar d'aplicar a altres contextos per enriquir-ne la comprensió.

El tercer bloc està constituït per quatre capítols, cadascun dels quals és dedicat al monacat femení en una regió concreta. En primer lloc, A. Rapetti analitza els monestirs a Venècia entre els segles X i XII, amb un interessant apartat dedicat a les motivacions que conduïren les dones devotes a la seva institució. A continuació, B.P. McGuire estudia les cistercenques en l'àmplia regió escandinava formada per Dinamarca i Suècia, presentant casos paradigmàtics de monestirs d'origen divers -fundació reial, antigues parròquies, etc.- i la seva relació amb el poder masculí. També se centra en un únic orde, però en aquest cas el de les clarisses, N. Jornet, que analitza el seu establiment a la Corona d'Aragó i cerca de fixar-ne un model propi en el context peninsular. Finalment, C. Florea aborda el monacat en la regió romanesa de Transilvània durant la baixa Edat Mitjana, i observa la preferència de les dones per certs ordes monàstics o mendicants segons les seves condicions socials i personals. 
Un quart bloc emfasitza la qüestió de l'espai, tant a nivell arqueològic com des de l'art. T. Collins s'acosta de forma suggerent al monacat femení a Irlanda a partir de l'arqueologia, presentant els resultats de les campanyes dutes a terme pel seu equip en diversos monestirs. Tot seguit, M. Carter analitza totes les manifestacions d'art cistercenc del monestir anglès de Swine, i en destaca la importància que patrons i benefactors hi tingueren. E.L. Jordan i A. Müller realitzen sengles investigacions sobre l'espai dels edificis monàstics i la seva simbologia: la primera ho aplica als Països Baixos, mentre la segona reflexiona sobre com entendre l'espai monacal i proposa noves investigacions al respecte. M. Untermann tanca la secció amb una interessant recerca sobre la situació dels cors en els monestirs alemanys.

Un darrer bloc inclou el capítol de H. Röckelein, en el qual presenta una pràctica eina per a l'estudi del monacat femení: la base de dades electrònica Female Monasticism's Database. Desenvolupada per la Universitat de Göttingen, incorpora dades dels monestirs femenins d'Europa al llarg de l'Edat Mitjana, des de la instauració del monacat el 400 fins a la Reforma protestant. L'objectiu és crear una fitxa per a cada fundació, de manera que ofereixi una base a partir de la qual iniciar la recerca. Evidentment, es tracta d'un projecte viu i en contínua actualització, però que, una vegada desenvolupat, promet de convertir-se en un instrument que facilitarà, en gran mesura, els estudis en aquest àmbit.

L'obra es completa amb un índex onomàstic i topogràfic que agilitza la cerca dins el volum. A part, cada capítol presenta la bibliografia citada en les pertinents notes a peu de pàgina, distingint-se entre manuscrits i fonts primàries i secundàries. Tot plegat dóna lloc a un abundant nombre de referències internacionals sobre el monacat femení per a tots aquells que desitgin ampliar la informació continguda.

La publicació d'aquesta obra té un valor afegit: inaugura una nova collecció de l'editorial Brepols. "Medieval Monastic Studies”, que tot just comença, pretén publicar investigacions sobre qualsevol aspecte del monacat europeu, tant obres generals com estudis de monestirs concrets, i a partir de les diverses disciplines que permeten acostar-s'hi. Així, es complementa la revista The Journal of Medieval Monastic Studies, apareguda el 2012, i que també editen Burton i Stöber. La qualitat d'ambdues publicacions queda garantida per la revisió a doble cec de tots els texts per part d'un consell editorial internacional format per una vintena d'especialistes d'universitats europees, americanes i d'Oceania. No en va, Brepols sempre ha cuidat tots els estàndards de qualitat científica que l'han convertida en una de les cases més prestigioses a l'hora d'editar obres en anglès. El primer títol de la col-lecció augura que seguirà pel mateix camí.

En definitiva, Women in the Medieval Monastic World és la darrera aportació a la història del monacat femení. S'han de felicitar els diversos autors per les seves investigacions i per la difusió que en fan, obrint noves vies de recerca. Així mateix, Burton i Stöber han dut a terme una intensa tasca editorial i han cuidat fins al darrer detall un volum que inaugura una nova col·lecció que arriba per esdevenir l'altaveu dels estudis monàstics europeus.

Albert CASSANYes RoIG Universitat de Lleida 
Pietro Colletta (ed.), Cronaca della Sicilia di Anonimo del Trecento, Leonforte, Euno Edizioni, 2013, CLXXXIII+413 pp. ISBN 978-88-6859-003-1.

La nova edició crítica de la Cronaca della Sicilia, publicada l'any 2013 per Pietro Colletta, Professor titular de filologia i literatura medieval-llatina i romànica a la Università degli Studi "Kore" d'Enna, va representar per a l'estudiós sicilià la culminació de la seva tesi doctoral. Un llarg i complicat projecte que va suposar molts anys de dedicació i estudi. La publicació de nombrosos articles científics sobre el mateix argument il·lustren prou bé les moltes dificultats que ha hagut de superar l'autor per identificar la complexa transmissió textual de la crònica i la seva importància històrica.

El resultat final d'aquests estudis va propiciar la publicació d'un gran volum titulat Storia, cultura e propaganda nel Regno di Sicilia nella prima metà del XIV secolo: la Cronica Sicilie, publicat a Roma per l'Istituto Storico Italiano per il Medio Evo, l'any 2011, dins de la col·lecció “Fonti per la storia dell'Italia medievale." Una obra magnífica que va despertar entre nosaltres l'interès de nombrós públic especialitzat (ressenyada en l'AEM 44/1 (2014), pp. 553-555; Estudis Romànics 36 (2014), pp. 467-617; Hispania LXXV, 249 (2015), pp. 269-308, entre altres). És un estudi excel·lent, fet amb rigor, el més complet i ben documentat de que disposem actualment sobre la gènesi i les circumstàncies de la redacció de la Crònica de Sicília. Una font històrica molt important que fins ara calia llegir principalment en l'edició de Rosario Gregorio, Bibliotheca scriptorum qui res sub imperio Aragonum gestas retulere, del 1792, però la qual era incompleta amb moltes llacunes i errors paleogràfics que comportaven la incomprensió del text en diverses parts.

La necessitat de posar fi a aquesta situació era ben evident i justificada, per això el professor Colletta, va fer de bell nou, una rigorosa edició crítica del text llatí de la crònica. La primera realitzada amb mètode crític, sòlidament recolzada en explicacions i aclariments exegètics $i$ històrics d'acord amb les tècniques modernes de la codicologia, de la paleografia i de la filologia textual. Finalment, l'any 2013, l'autor va publicar la nova edició crítica de la Cronica Sicilie, objecte de la nostra atenció.

L'obra està precedida d'una amplia introducció molt tècnica, dividida en quatre apartats. El primer tracta de manera resumida de la gènesi, datació, estructura $i$ ideologia de l'obra, aspectes que ja foren àmpliament desenvolupats en el primer volum. Destaca que les Vespres i els esdeveniments polítics, diplomàtics i militars que es van viure a Sicília a partir d'aquell moment, van impulsar una significativa producció historiogràfica en llatí, caracteritzada per una implicació notable en el pla literari i ideològic dels seus autors. A més de la Cronica Sicilie d'autor anònim, destaquen la Historia Sicula de Bartolomeo de Neocastro, el De gestis Siculorum sub Federico rege et suis de Niccolò Speciale i la Historia Sicula de l'anomenat Michele da Piazza. La composició i circulació d'aquestes obres representa un fenomen cultural molt peculiar de Sicília que no té contraposició amb l'antagonista Regne de Nàpols. Aquesta esponerosa historiografia fou deguda molt probablement a l'exigència de legitimació del regne sicilià, nascut el 1282 fruit de la secessió, i que va culminar amb la coronació de Frederic III l'any 1296. La Cronica Sicilie és la més oficial i afortunada d'aquestes cròniques, segons demostra Pietro Colletta. Es va escriure molt probablement durant el decenni que va entre la mort de Frederic III (1337) i l'esclat de la Pesta Negra l'any 
1347 i principis de 1348. Cronològicament comprèn des del 1282, any de les Vespres Sicilianes, fins al 1347, just al començament de la Pesta Negra.

En el segon apartat de la introducció, l'autor analitza la transmissió manuscrita de la Cronica Sicilie per reconstruir les fases de redacció de l'obra que segons ell són quatre: la primera fase arriba fins l'any 1338 amb 105 capítols; la segona fase fins a l'any 1343 i sense modificar el text precedent s'hi afegeixen 11 capítols nous, que sumats als anteriors fan 116 en total; la tercera redacció va continuar fins el 13471348, afegint 9 capítols, que en total fan 125; la quarta redacció seria partir del capítol 109 de la crònica fins al final, on abunden interpolacions i modificacions que alteren el contingut original del text.

Per altra banda, el nombre total de manuscrits que contenen la crònica en les diferents redaccions o versions compendiades és de 10. Una vegada estudiats individualment, la conclusió és que els testimonis útils per a la fixació del text sobre el que es basa la nova edició crítica són només dos manuscrits: $\mathrm{V}$ que és el testimoni millor encara que no el més complet, i B que té algunes particularitats divergents. La col-lació entre ambdós ha descobert que B presenta en certs punts, un text més ampli fruit probablement d'interpolacions a partir del capítol 109 en endavant, on el text apareix completament modificat en relació a V, i fet l'acarament d'aquest manuscrit amb el que conté la traducció catalana de la crònica, dedueix que la part final de $\mathrm{B}$ és una reelaboració fins ara inèdita de la que tenim constància directa gràcies a la traducció catalana de la Crònica Sicilie, de la que no s'ha conservat la versió original llatina sinó una reelaboració a través del còdex B. De fet, l'autor la considera, una quarta redacció perquè presenta modificacions significatives i alguna interpolació en la part final de la crònica, com ja s'ha dit. En l'edició crítica d'aquesta part final s'ha considerat oportú seguir el text de B, en tant que és codex unicus. Ambdós manuscrits eren desconeguts als editors precedents així que és un gran mèrit de Pietro Colletta aquest descobriment.

El tercer apartat tracta de forma molt detallada de les edicions modernes de la Cronica Sicilie des del segle XVIII fins a l'actualitat, i també sobre les edicions de documents inserits dins del text narratiu que donen un caràcter diferent a la crònica i molt probablement són les que han determinat la seva fortuna. El resultat és molt interessant ja que es fusionen motius ideològics de fonts integrades entre elles d'una manera nova i original. La bibliografia és molt completa i ben seleccionada, utilíssim l'índex de persones i de llocs.

En el quart apartat es revisen els manuscrits que no s'han pres en consideració (Codici deteriori) que no detallem aquí. S'estableix l'stemma codicum, destacant bé les tres redaccions successives de la crònica: 1338, 1343 i 1347-1348, i la reescriptura de la part final.

Segueix l'edició crítica de la Cronica Sicilie feta amb gran cura i rigor filològic. Conté anotacions precioses per entendre les nombroses interpolacions al text primitiu que foren afegides posteriorment amb molts errors sobre la identificació de noms de personatges i de topònims. Aquesta edició presenta una lectura nova en moltes parts, de tal manera que serà necessari revisar algunes coses que s'havien dit fins ara sobre els fets ocorreguts a Sicília durant les Vespres i els anys posteriors, des de la consolidació i posterior caiguda del domini de la Casa d'Aragó a l'illa siciliana. 
Cal, doncs, felicitar calorosament Pietro Colletta per l'edició crítica de la Cronica Sicilie, una de les obres més singulars de la historiografia siciliana del segle XIV, que va fer servir la història per enaltir la monarquia i la dinastia de la Casa d'Aragó que legítimament en garantia la continuïtat. Tanmateix, el quadre històric-cultural que s'hi reflecteix no queda limitat a l'àmbit sicilià, sinó que es contraposa amb altres tradicions historiogràfiques -de la Itàlia comunal, de la Corona d'Aragó, del regne de França o de les Illes Britàniques- obrint una perspectiva interpretativa d'àmbit europeu molt interessant i renovadora. En definitiva, una obra de referència obligada per als historiadors de la Guerra del Vespro Sicilià.

MONTSERRAT CASAS NADAL Universitat de Barcelona

Élisabeth CROUZET-PAVAN, Renacimientos italianos (1380-1500), Valencia, Universitat de València, 2014, 558 pp. ISBN 978-84-370-9232-4.

La medievalista francesa Élizabeth Crouzet-Pavan, profesora de la Sorbona y reconocida especialista en la historia bajomedieval italiana, nos ofrece en este libro una apretada síntesis de los aspectos más relevantes de la evolución histórica de Italia durante el siglo XV, planteada a partir de múltiples y sugerentes reflexiones en torno a lo que representó el fenómeno del Renacimiento. Ante todo se esfuerza por llamar nuestra atención sobre la necesidad de desmitificar este concepto, y de asumir una visión del mismo mucho más matizada, que tenga en cuenta sus numerosas contradicciones y contrastes. Para ello pone el acento, por un lado, sobre las muchas novedades y rasgos originales que cabe percibir en la Italia del Cuatrocientos, pero, por otro lado, insiste en recordarnos que al mismo tiempo se detectan en este mismo ámbito en dicho período múltiples realidades que denotan continuidad y persistencia de estructuras anteriores.

El libro resulta enormemente pródigo en informaciones, pero, más que por su carácter enciclopédico, ofrece interés por la originalidad de las reflexiones de las que nos hace partícipes la autora, relativas al significado de los procesos históricos analizados, de gran valor para el enriquecimiento del debate historiográfico. Se estructura en ocho capítulos, a los que se suma una breve conclusión y las habituales tablas cronológicas, mapas, relaciones de bibliografía primaria y secundaria, e índices.

Los dos primeros capítulos abordan las cuestiones de carácter más general sobre el significado del fenómeno del Renacimiento como movimiento cultural y artístico que se planteaba a sí mismo como de radical renovación. El primero en concreto se centra en el análisis de la faceta positiva de un proceso en virtud del cual la sociedad italiana del siglo XV se vio progresivamente dominada, en palabras de la autora, por el "sueño de una compleja renovación cultural", que destiló orgullo y optimismo, y se presentaba a sí misma como una reconquista del pasado antiguo, una resurrección de Roma. El capítulo segundo, por contraste llama la atención sobre las limitaciones de dicha "renovación", poniendo de manifiesto la persistencia de numerosos elementos que, en términos metafóricos, son caracterizados como "sombras del pasado", pero no del antiguo sino del medieval. 
Los capítulos tercero y cuarto están dedicados al estudio de las estructuras políticas, y en ellos se pasa revista a una amplia gama de cuestiones de enorme interés para la historia comparada de las relaciones de poder en el conjunto de la Europa occidental, por el esfuerzo que realiza la autora a la hora de poner de relieve los rasgos que más contribuyen a definir la originalidad de la situación italiana en el contexto europeo, resaltando al mismo tiempo la enorme diversidad interna del espacio italiano, que se encontraba muy fragmentado. Detecta las grandes líneas de evolución de la vida política a lo largo del siglo XV, llamando la atención sobre el generalizado avance de las formas de ejercicio personal del poder, paralelo al retroceso de las repúblicas y a la simplificación del mapa político, por efecto de la consolidación de un número más reducido de estados regionales que conformaron un sistema de frágil equilibrio, caracterizado por la coexistencia de actores de muy diversos rangos y perfiles, tanto entre los príncipes como entre las repúblicas, quienes en ningún caso lograron detentar el monopolio del poder en el conjunto de sus respectivos territorios. Reflexiona también sobre el papel que en la vida política desempeñaron las guerras, en las que los condottieri asumieron un papel protagonista, y el ejercicio de la violencia, deteniéndose en el análisis de algunos paradigmáticos ejemplos de recurso a la violencia política. Y, por fin, también se ocupa de la caracterización de los discursos políticos, centrándose en dar cuenta de la polémica planteada entre los defensores del modelo republicano, desde Florencia y Venecia, y los que se posicionaron a favor de la tiranía, es decir, del gobierno de los príncipes, que tuvieron en Milán su epicentro.

Las estructuras económicas son objeto de análisis en el quinto capítulo, en el que también se hace referencia a fenómenos de interés desde la perspectiva general de la historia de Europa y de sus relaciones con Oriente, pues no en vano los italianos desempeñaron un papel puntero en el desarrollo del comercio y las finanzas durante el período medieval. Desde la perspectiva temática central del presente libro este capítulo resulta, sin embargo, el de menor interés, porque, como reconoce la autora, en los estudios sobre el Renacimiento la economía no ha ocupado un lugar central, por haber prevalecido en ellos los análisis sobre los factores culturales, que eran los que se consideraba que mejor sintetizaban dicha categoría historiográfica. Resulta, en efecto, mucho más difícil detectar en el ámbito de las estructuras económicas del Cuatrocientos italiano las manifestaciones de radical cambio o renovación que se prodigaron allí entonces en otras esferas de la realidad histórica, muy en particular en la cultural. Y, como consecuencia, también ofrece mayor dificultad detectar los rasgos que desde la perspectiva de la historia económica conferirían su originalidad a esta centuria en Italia respecto a las anteriores y posteriores. A pesar de todo, las páginas dedicadas a esta cuestión no carecen de interés, y en ellas podemos aprender bastante sobre la extraordinaria diversidad que desde el punto de vista del desarrollo de las actividades económicas caracterizó al mundo italiano bajomedieval.

Las estructuras sociales son el objeto de atención preferente de los capítulos sexto y séptimo, que también pasan revista a una amplia y diversificada gama de cuestiones, de entre las que destacaremos las principales. En concreto dedica la autora sugerentes reflexiones al problema del desarrollo del individualismo, considerado como uno de los rasgos más originales y novedosos de la cultura renacentista. 
Y lo hace deteniéndose en el análisis iconográfico de la abundante producción de retratos, individuales y colectivos, que nos ha legado la Italia del siglo XV, y también en la reconstrucción de los cambios acontecidos en las condiciones de vida y trabajo de los artistas, que, no obstante, insiste en recordarnos que no fueron unidireccionales ni avanzaron al mismo tiempo en todas partes. Por otro lado, también aborda el análisis de esta misma problemática prestando atención a un tipo de literatura que alcanzó enorme difusión en esta época, la que agrupa a las crónicas familiares o libros de ricordi.

Otro aspecto de las estructuras sociales italianas del siglo XV que atrae sobre manera la atención de la profesora Crouzet-Pavan es el de la proliferación de leyes suntuarias detectado en dicha centuria, que interpreta como un esfuerzo de la autoridad pública por disciplinar y moralizar el cuerpo social, aunque con escaso éxito, a juzgar por la abundancia de indicios sobre su constante incumplimiento. Las leyes suntuarias, en efecto, no perseguían exclusivamente un objetivo económico, el de intentar limitar las inversiones no productivas, sino que también buscaban hacer frente a los nuevos desafíos a la moralidad pública, y de ahí que su análisis proporcione ocasión a la autora para abordar el tratamiento de otros muy variados aspectos de la vida social, tales como la política matrimonial, la gestión de los patrimonios familiares, las prácticas sexuales, o la percepción de las mujeres y los jóvenes por la mayoría social dominante.

Otro aspecto clave de las estructuras sociales italianas del Cuatrocientos al que se dedican varias páginas en el capítulo séptimo es el de la caracterización del grupo noble, que se nos presenta como extraordinariamente diversificado, y conformado por la coexistencia de identidades múltiples.

El capítulo octavo, por fin, vuelve otra vez a insistir en poner de relieve el carácter ambiguo de la realidad histórica italiana durante el Renacimiento, al centrar su atención en el análisis de la religiosidad, que da pie a la autora para demostrar que, junto a la irrupción innovadora del humanismo, persistieron con fuerza las creencias religiosas de clara raigambre medieval, a la vez que continuaron manifestándose con vigor los movimientos mesiánicos y escatológicos. De ahí que acabe concluyendo que la sociedad italiana renacentista fue profundamente paradójica y contradictoria, porque nunca logró superar la tensión planteada entre visiones optimistas del mundo con otras de decidido sesgo pesimista, en tanto que consideraban que estaba abocado a desaparecer en breve plazo de tiempo.

En suma, pues, nos encontramos ante una magnífica obra de síntesis sobre la historia de unos de los territorios más fecundos en aportaciones a la civilización europea, en un período clave de su evolución, el siglo XV. Y también ante una obra muy original, en la que abundan las interpretaciones novedosas, y se ponen en cuestión algunos de los tópicos más arraigados en torno a la caracterización del Renacimiento, al tiempo que se nos ofrece una visión mucho más matizada y menos idealizada del fenómeno de la que cabe encontrar en la historiografía "clásica".

MáXimo Diago HeRnANDO Instituto de Historia, CSIC. Madrid 
Arnold EsCH, Die Lebenswelt des europäischen Spätmittelalters. Kleine Schicksale selbst erzählt in Schreiben an den Papst, München, Verlag C.H. Beck, 2014, 544 pp. ISBN 978-3-406-66770-1.

Arnold Esch és un historiador amb una àmplia formació i trajectòria, fou professor d'història medieval a la universitat de Berna, és o ha estat membre de diverses acadèmies alemanyes i de la Pontificia Accademia Romana di Archeologia, així com director del Deutschen Historischen Instituts (DHI) de Roma (entre 1988-2001) i membre de l'equip coordinador dels Monumenta Germaniae Historica.

El seu interès per la història de les ciutats italianes (obtingué l'habilitació a partir d'un estudi sobre Lucca), el papat i la Renaixença italiana, a banda d'altres temes vinculats a l'arqueologia, es fa palès a partir de les darreres obres publicades: Wiederverwendung von Antike im Mittelalter. Die Sicht des Archäologen und die Sicht des Historikers (2005), Landschaften der Frührenaissance. Auf Ausflug mit Pius II (2008), Zwischen Antike und Mittelalter. Der Verfall des römischen Straßensystems in Mittelitalien und die Via Amerina (2011).

L'obra actual és continuadora d'una altra, publicada fa pocs anys, amb el títol Wahre Geschichten aus dem Mittelalter (München 2010) i el mateix subtítol que el llibre que ara ressenyem. Ambdós llibres són fruit d'una intensa recerca documental en el ric fons de l'Arxiu de la Penitenzieria Apostolica. No cal ser endeví per imaginar que seria durant els anys que Esch féu estada a Roma quan degué realitzar el buidatge sistemàtic de la documentació que conforma la base dels dos treballs indicats. L'obra en qüestió ha estat confegida a partir d'una selecció de milers de súpliques adreçades a la susdita oficina papal, les quals es poden agrupar en tres categories: absolucions, dispenses i llicències. D'un total de 33.000 documents regestats, l'autor n'ha aprofitat, en aquesta ocasió, al voltant de 2.400. Cal fer avinent que una part d'aquest fons documental es troba recollit, almenys pel que fa a l'àmbit imperial, al Repertorium Poenitentiariae Germanicum (publicació a càrrec del DHI), amb vuit volums apareguts fins a la data, cobrint successius pontificats del segle XV a partir d'Eugeni IV.

Aquest cop l'àmbit territorial no es limita a l'Europa central (l'anterior llibre "només" abraçava l'Imperi germànic i zones limítrofes) sinó tota la resta d'Europa, fent especial incidència en la Península Italiana, a banda d'altres territoris perifèrics. En relació amb la Península Ibèrica, s'inclouen referències a Aragó, Barcelona, Lleida, Mallorca, Menorca, Tortosa, València, Saragossa, Tarassona..., també a Pamplona/ Navarra, a més d'una llarga llista de ciutats castellanes, com Sevilla, Toledo o Santiago de Compostela, per citar-ne només algunes. Quant a personatges, trobem mencions als papes Borja, a Alfons V d'Aragó i els Reis Catòlics, Ignasi de Loyola i Francisco de Carvajal, aquest darrer a propòsit de la seva participació al sacco di Roma. Encara que el període considerat estigui teòricament comprès entre el 1439 i el 1484, el llibre s'estén cronològicament fins a l'esmentat succés de 1527.

L'obra en qüestió consta de 14 capítols, el primer dels quals és dedicat a explicar el funcionament de la institució de la Penitenciaria i a fer una valoració heurística de la documentació emprada, cosa que es complementa amb el capítol novè, on s'incideix en diversos aspectes tocants a la forma narrativa de les súpliques. La resta de capítols es distribueix en diversos blocs temàtics, començant per l'àmbit domèstic i la família (cap. 2), seguint per diferents aspectes de la vida social o comunitària 
(cap. 3) i l'exercici de l'autoritat (cap. 4), i altres capítols concernents a Església i clergat (cap. 5), vida monacal (cap. 6), àmbit universitari (cap. 7), heretgia i bruixeria (cap. 8), àmbit mediterrani (cap. 11), amb qüestions relacionades amb el comerç i amb les croades contra els turcs; pelegrinatges (cap. 12), incloent-hi un subapartat relatiu al Camí de Sant Jaume; guerra i pesta (cap. 13), continuant pels diversos conflictes bèllics de l'època (cap. 14), i encara un capítol sencer (el 10) dedicat a Itàlia, amb un subapartat sobre el regne de Nàpols. Els títols adjudicats als subapartats de cada capítol poden donar una major idea de la diversitat de qüestions abordades al llarg de l'obra.

A cada un dels apartats hi trobem exposades petites històries basades en vivències personals d'individus de diferents orígens i condició social, tant laics com eclesiàstics. En molts casos, es tracta de breus apunts respecte de situacions de les quals no es donen més detalls, talment com si fos material de reserva per a futurs llibres; en canvi, altres casos conformen relats més extensos, incloses transcripcions de les declaracions dels demandants. En el parer de l'autor, la font emprada, més que no pas oferir una reconstrucció de fets, permet endinsar-se en la idiosincràsia de les persones mitjançant una aproximació que moltes altres fonts de l'època no poden oferir. Hi ha casos referits a curioses peripècies, molts altres es relacionen amb situacions conflictives o amb afers delictius, com ara robatoris i actes criminals, o bé són històries completament banals i representatives de situacions molt corrents. Així i tot, no es tracta d'un simple recull d'anècdotes, ni del típic estudi acadèmic restringit a especialistes (no hi ha tractament estadístic de la informació), sinó més aviat d'una obra gairebé novel-lada i orientada cap a un públic força més ampli, amb inclusió d'algunes il·lustracions i una afinada contextualització dels diferents casos exposats. En realitat, no estem gaire allunyats de la literatura medieval de relats, fins al punt de poder establir alguns punts de connexió -així ho fa l'autor- amb els contes de Boccaccio i de Chaucer.

Els següents casos referents a localitzacions hispàniques poden servir com a botó de mostra dels diferent tipus de relats que hi trobem exposats.

Segons es comenta al capítol 3 (p. 86), a la diòcesi de Saragossa hi havia el costum de festejar la primera celebració de missa d'un sacerdot amb diversos jocs i entreteniments. El peticionari de la súplica, un clergue d'aquesta zona, explica que fou convidat junt amb altres a participar en una d'aquestes activitats lúdiques, concretament, a competir a veure qui podia saltar més alt amb una pedra a cada mà; per desgràcia, una de les pedres li relliscà de les mans de tal manera que anà a impactar al front d'un jove. No s'indica quin desenllaç tingué aquest succés, com sí que es fa avinent a propòsit d'altres accidents mortals comentats al llibre. Certament, es tracta d'un fet anecdòtic, però que serveix per retratar una escena de la vida comunitària.

Per altra banda, s'inclouen algunes històries escabroses com la següent: dins l'apartat "Execucions" (p. 110) s'explica com uns sarraïns de la ciutat de Mallorca, havent estat condemnats per un suposat emmetzinament de fonts, foren penjats dels peus i lapidats fins a la mort per la quitxalla i jovent de la ciutat. En aquest fet, ocorregut ja feia temps (no s'indica la data), hi havia participat el declarant, i per bé que no s'indiqui explícitament, es pot deduir que devia demanar-ne l'absolució.

Al capítol 4 (p. 118) es parla del mal costum -en el parer del declarant-que hi havia al regne de Castella cada vegada que el rei visitava una ciutat, ja que els nobles i prelats del seu seguici obtenien allotjament gratis, segons que els era assignat 
pels oficials reials en funció del seu rang o títol. Quan el monarca visità Medina del Campo, el peticionari, que era funcionari del rei de Navarra, anà a la casa d'un prevere per assignar allotjament a un escuder, però aquell i altres preveres s'atrinxeraren a la casa amb armes i fins i tot feriren de mort un navarrès; finalment, el peticionari, juntament amb un grup d'escuders, irromperen a l'habitatge, mataren un dels clergues $i$ en feriren un altre.

Dins el subapartat “Monestir i món” (pp. 190-191), es documenten moltes sol-licituds de religioses de diferents ordes que demanaven llicència per visitar balnearis per raons de salut, fins i tot tenint prescripció mèdica. Es destaca especialment el cas de les clarisses del convent barceloní de Pedralbes; l'autor ha registrat, sobretot de l'època del papa borgià Calitx III, nombroses sol-licituds realitzades per les monges d'aquest convent, inclosa l'abadessa, encara que no s'indica cap localització en concret.

Dins “Troballes màgiques” (p. 214) es dóna a conèixer el cas d'un clergue de la diòcesi de València que declarà que, de jove, havia viscut a la ciutat d'Almeria com a presoner dels musulmans. Gràcies a un vell sarraí, s'havia assabentat d'un amagatall d'or que hi hauria en un determinat indret del regne de València, de l'època en què aquest territori havia estat sota domini andalusí. Un cop alliberat, tornà a la seva terra i intentà localitzar el tresor amb la col·laboració d'altres persones que tenien coneixements de nigromància, però tot fou endebades.

Dins el subapartat "Petits trànsits per la frontera de Granada" (p. 321), s'explica un cas esdevingut el 1472, en què un home de Jerez de la Frontera, en el marc d'unes bandositats entre la noblesa local, havia donat com a ostatges dos dels seus fills. Per tal d'aconseguir alliberament, acabà fent tractes amb els musulmans, als quals lliurà diversos articles, incloent-hi algunes armes, cosa que li reportà de ser excomunicat. No en va, el comerç prohibit amb els països islàmics és una de les qüestions abordades al principi del capítol XI.

Dins també el capítol dedicat al Mediterrani (p. 343), s'explica el cas d'un motí que s'havia produït en dues galeres del rei d'Aragó comandades, i això és força curiós, per un frare carmelita fugitiu, que posteriorment havia retornat al seu convent. Els remers, tots ells esclaus, intentaren matar els oficials, i gairebé ho haurien aconseguit si aquests altres no haguessin reaccionat de forma contundent, provocant la mort de set rebels.

Naturalment, el llibre inclou molts altres exemples relacionats amb el món hispànic. Amb tot, seria recomanable de fer-ne una lectura tan àmplia com fos possible perquè, deixant de banda el caràcter amè de molts dels seus passatges, tot el que s'hi exposa és una veritable auca il·lustrativa de com era la vida dels homes i les dones d'aquella època, de les dificultats i problemes amb què s'havien d'afrontar quotidianament, de les seves creences i supersticions, o de determinades pautes i formes de comportament social, entre molts altres aspectes d'interès. Tot plegat ens ofereix una visió molt "real" de l'Europa del segle XV, configurant una història de petites històries, amb les persones com a protagonistes principals. 
Francesco GUIDI BRUSCOLI, Bartolomeo Marchionni "homem de grossa fazenda" (ca. 1450-1530). Un mercante fiorentino a Lisbona e l'impero portoghese, Firenze, Leo S. Olschki, 2014, XXVI+272 pp. (Biblioteca storica toscana; 73). ISBN 978-88-222-6300-1.

L'étude de Francesco Guidi Bruscoli est dédiée à l'homme d'affaires florentin Bartolomeo Marchionni et à son rôle dans le développement de l'Empire portugais de la fin du XVe siècle au milieu du XVIe siècle. Elle est le résultat d'une recherche méticuleuse et intensive dans un nombre assez impressionnant d'archives en Italie, en Espagne et au Portugal, démontrant les capacités paléographiques et philologiques de l'auteur, et mettant à la disposition de la communauté des chercheurs une riche documentation.

Le livre comprend deux parties. La première partie est centrée sur la vie et les collaborateurs de l'homme d'affaires florentin. Elle est divisée en deux chapitres. Le premier retrace la biographie de Marchionni, de sa naissance à Florence vers 1450 à son décès à Lisbonne peu avant 1530. Son entrée dans la compagnie Cambini en 1466 fut à la base de son implantation définitive au Portugal puisque c'est dans ce cadre qu'il arriva à Lisbonne en 1470. Ses succès économiques et les liens qu'il tissa avec le milieu marchand portugais comme avec l'élite et la Couronne lui permirent d'obtenir une série de privilèges qui culminèrent avec la naturalisation portugaise octroyée par Jean II en 1482, au moment où s'ouvrait à Florence, au Tribunal de la Mercanzia, la procédure de faillite du banco Cambini. La carta de naturalizado, en faisant de Marchionni un sujet portugais, le plaçait à l'abri d'éventuelles poursuites judiciaires. En évoquant paralèlement la vie privée et la descendance du marchand, l'auteur présente une famille de plus en plus enracinée et de plus en plus portugaise. Le second chapitre est dédié à son vaste réseau de collaborateurs et de correspondants actifs en Méditerranée comme dans l'Océan atlantique. Grâce à une riche documentation l'auteur dresse le portrait de ces personnages qui gravitaient autour de Marchionni à Lisbonne, en Espagne (Séville, Valence), dans les îles atlantiques (Açores, Madère), à Venise et dans les places financières de Lyon et de Bruges. Même si Marchionni était au cœur d'une rete sovra-nazionale di relazioni di cui i mercanti fiorentini costituivano elementi essenziali (p. 76), il développa également d'intenses collaborations avec des opérateurs portugais et génois.

La seconde partie explore en trois chapitres les activités commerciales et financières du marchand-banquier florentin. Le premier s'ouvre sur le commerce européen et le monde atlantique et met en valeur la riche documentation comptable de la compagnie Cambini, conservée dans l'Archivio dell'Ospedale degli Innocenti à Florence. Lisbonne, à mi-chemin de la route maritime reliant la péninsule italienne aux marchés de l'Europe du Nord-Ouest (Angleterre, Flandre), était un centre majeur d'import-export. Le troc (baratto) était au cœur des échanges impliquant les produits européens (principalement des tissus), les produits africains (or, poivre, tissus nordafricains troqués ensuite en Mauritanie et en Sénégambie), les produits des îles atlantiques (orseille, sucre de Madère) et le bois-brésil. Marchionni était même impliqué dans le circuit de production du sucre de Madère qui prenait ensuite principalement la direction de la Flandre et de Venise. Il saisit aussi les opportunités économiques se présentant à lui et s'intéressa dès le début au Brésil, finançant une des embarcations de Pedro Alvarez Cabral qui, en 1500, accosta pour la première fois sur les côtes 
brésiliennes. Le commerce des esclaves est l'objet d'un deuxième chapitre, où sont analysés les coûts et les profits, et l'implication de Marchionni dans l'importation d'esclaves africains vers l'Europe occidentale (Valence, Séville, mais également Florence), à travers la plaque-tournante portugaise. Enfin, le dernier chapitre se tourne vers l'Asie et le commerce des épices. L'auteur y dépeint l'implication financière de Marchionni dans plusieurs voyages de la Carreira da Índia, dont les expéditions des célèbres capitaines comme Pedro Alvarez Cabral, Vasco de Gama ou Francisco de Almeida, dont il décrit les voyages. L'auteur s'arrête également sur l'acquisition des épices sur les marchés orientaux (notamment poivre, cannelle, clous de girofle), leur transport, leur vente à Lisbonne et leur réexportation sur les marchés européens.

L'auteur conclut son volume avec un riche appendice comprenant 19 documents issus de fonds d'archives italiens, portugais et espagnols, dont certains sont totalement inédits. Les documents, présentés de manière chronologique, permettent de suivre les différentes étapes du parcours de Marchionni, du privilège octroyé par Alphonse V en 1475 à une licence d' "amdar em mula" concédée par Jean III en 1522, en passant par l'acte de naturalisation de 1482.

À travers une approche très classique, Francesco Guidi Bruscoli emmène le lecteur explorer aux côtés de Bartolomeo Marchionni les premières expéditions commerciales dans des continents encore à découvrir, où l'enthousiasme des Florentins en direction du continent asiatique contrebalançait la frilosité de la société portugaise qui préférait investir dans le commerce atlantique. S'il n'avait encore jamais fait l'objet d'une monographie exhaustive, Marchionni n'est absolument pas un inconnu pour les historiens qui se penchent sur le grand commerce des XVe et XVIe siècle. De nombreux auteurs, comme Federigo Melis, Virginia Rau, Jacques Heers, Marco Spallanzani ou plus récemment Sanjay Subrahmanyam, lui ont dédié de nombreuses pages. Le livre de Francesco Guidi Bruscoli comble cette lacune historiographique à travers une étude en profondeur sur cette figure emblématique et, au-delà, sur le rôle des agents florentins et de leurs réseaux dans l'établissement de l'empire commercial portugais. Si l'auteur reconstruit de manière très détaillée le portrait de l'homme d'affaires florentin et de ses collaborateurs, il aurait été intéressant d'ajouter à la reconstruction de ces stratégies et de ces réseaux commerciaux un chainon majeur constitué par les populations indigènes d'Afrique et d'Inde avec lesquelles les marins et les marchands européens devaient interagir.

INGRID HOUSSAYE MICHIENZI The Harvard University Center for Italian Renaissance Studies

Eduard JunCOSA BONET, Estructura y dinámicas de poder en el señorío de Tarragona. Creación y evolución de un dominio compartido (ca. 1118-1462), Barcelona, Consejo Superior de Investigaciones Científicas, 2015, 494 pp. (Anejos del Anuario de Estudios Medievales; 74). ISBN 978-84-00-10035-3.

A pesar del estudio pionero de L.J. Mc Crank, y de aportaciones posteriores, la historia del doble poder (arzobispal y condal-real), en el señorío de Tarragona merecía ser investigada a fondo, y para toda la Edad Media, en una 
nueva y amplia monografía. Lo requería la originalidad e importancia del caso, y las dificultades de funcionamiento inherentes a una estructura de estas características, que habían de derivar en una dinámica de tensiones y conflictos entre señores, oficiales y vasallos.

La obra que reseñamos, versión resumida de la tesis doctoral del autor, contiene implícitamente una hipótesis y una demostración, y se inserta en una investigación de gran alcance sobre la idea de la "libertad" y, en concreto, de las "libertades urbanas". El autor se enfrenta al reto de saber cuándo y cómo Tarragona empezó a construir su futuro como ciudad, en el sentido moderno del término. La hipótesis es que, a pesar del doble poder señorial englobante, que hace de la historia tarraconense una historia singular, el proceso empezó en la plena Edad Media.

Evidentemente, la ciudad no es una suma de personas o familias, ni un volumen de negocio, aunque todo esto cuente, es ante todo un proyecto colectivo que se construye consciente o inconscientemente a través del ejercicio de la libertad. Una libertad que avanza y retrocede, según las fuerzas que se le oponen, y que al cabo, si es posible, se amplia y consolida. Este anhelo de libertad ciudadana es lo que hace la ciudad. Y Juncosa, con la ayuda de una documentación extraordinaria, que selecciona con acertado criterio y transcribe con maestría, demuestra que la utopía de la "libertad" está presente en la Tarragona que estudia. Y es un misterio que en un mundo dominado por señores celosos de sus poderes pudiera despertarse en las clases populares una esperanza de "libertad".

Hablamos de un proceso lento e indefinido de adquisición de derechos, que hace a los hombres más dueños de sí mismos, y por tanto más libres en sus decisiones. Para que se entienda: en muchas páginas de este libro, y de un modo especial en los documentos emanados del Consejo de la ciudad se aprecia una respiración predemocrática, en el sentido de los inicios de un proceso muy largo y complejo, lleno de vicisitudes, que al cabo de los siglos habrá de llevar a la constitución de gobiernos urbanos democráticos.

¿De dónde surge este anhelo de "libertad”? La respuesta no es simple, pero se obtiene a través de los sucesivos capítulos del libro. La investigación comienza con los proyectos de conquista del siglo XI, y el estudio del origen del régimen coseñorial tarraconense y de sus formas, vicisitudes y violencias, en el siglo XII. Ya entonces los tarraconenses recibieron una carta dual de libertades (1149), que Alfonso el Casto a finales del siglo XII y Pedro el Católico a principios del XIII ampliaron. Estas concesiones debieron hacerse por la necesidad de consolidar el poblamiento y la vida económica de la ciudad, y muy probablemente también porque los tarraconenses lo querían o exigían. ¿Cómo interpretar sino las revueltas populares de 1276 y 1280 contra el poder del arzobispo que los reyes ayudaron a sofocar?

Confirmando la aparición del protagonista de fondo de la obra, el ciudadano, el microscopio del investigador se centra a continuación en la población de la ciudad y de su veguería. Se trata de saber cuántos eran y dónde estaban. Es un capítulo breve pero difícil por la problemática que los fogatges encierran, como instrumentos fiscales de uso demográfico. De su contenido se deduce que Tarragona sufrió duramente los efectos de la crisis del siglo XIV, al punto de perder la mitad de su población y quedar, dice Eiximenis, como una ciudad pobre y miserable. 
Esta postración explica seguramente el muro contra el que se estrellaron los anhelos de mayor libertad de los tarraconenses a finales de la Edad Media. Mención especial merece la nota 56 de este capítulo donde Juncosa recoge una muy interesante noticia sobre la hambruna de 1333-1334, sin parangón en la memoria de los hombres dice la fuente. Hambruna que fue acompañada de una terrible alza de precios, que el arzobispo intentó mitigar importando cereal de Valencia y distribuyéndolo entre los hambrientos.

El siguiente capítulo, muy largo, es verdaderamente neurálgico en la estructura de la obra. Se dedica a los orígenes, organización y desarrollo del gobierno municipal. En él se demuestra que fue durante los siglos XIII y XIV cuando, desde el plano político, Tarragona se convirtió definitivamente en ciudad. Ciertamente los reyes (sobre todo Jaime I), y en menor medida los arzobispos, actuaron de creadores del régimen municipal que acabó de dar forma a la entidad política ciudadana. El autor es consciente de las plurales impulsiones que llevaron a esta eclosión: alude, como no podía ser de otro modo, a la recepción del ius comune y a la política municipalista de Jaime I, seguida por Pedro el Grande, que había empezado en Valencia y Barcelona, y que se extendería a otras ciudades como Tarragona. Pero es claro, y a Juncosa tampoco se le escapa, que había una voluntad ciudadana subyacente, un anhelo de "libertad", decíamos, que se expresaba en súplicas y peticiones de privilegios. La cuestión sería saber por qué los reyes lo tuvieron en cuenta. No se trata de especular sobre razones políticas, económicas o de sentido de la responsabilidad. No es nuestro cometido en esta reseña aunque el estudio de Juncosa invite a ello. Nos limitaremos a señalar que esta obra aporta información sobre lo que podríamos llamar patriotismo urbano, un orgullo de pasadas grandezas que los restos romanos perpetuaban en la memoria de los ciudadanos de Tarragona. Añadiremos que aflora entonces una conciencia de grupo, con necesidades y aspiraciones compartidas, que jurídicamente está cristalizando en un conglomerado de derechos y deberes colectivos, una res publica, concepto que el autor subraya. A finales del siglo XIV los tarraconenses se querían tan dueños de sí mismos que, "para utilidad y bien de la cosa pública", incluso prohibieron la presencia en el Consell (el parlamento urbano) de oficiales y domésticos del arzobispo y del rey. Juncosa lo explica. De las importantísimas funciones que competían al gobierno de los ciudadanos y que el autor expone retendremos la de asegurar el abastecimiento cuando las carestías.

Después sigue un capítulo más bien breve dedicado a la simbología del poder, en el que se describen los pormenores de las ceremonias de entrada del rey y el arzobispo en la ciudad. La liturgia para la ocasión era costosa, pero debía servir, en la proximidad, para agradecer liberalidades y reforzar los lazos entre los vasallos y sus señores. Este ceremonial de culto a la autoridad seguramente perseguía fomentar sentimientos de adhesión del pueblo a su señor y de estímulo del paternalismo señorial.

De sumo interés es el capítulo dedicado al derecho de ciudadanía. Aquí, en palabras de los propios ciudadanos, aparece muy claramente expresado este milagro del espíritu humano que es la noción de bien común, auténtica alma de la ciudad. Un fascinante documento municipal de 1429 o 1430 que Juncosa reproduce (p. 252) comienza con dos ideas clave para la demostración que implícitamente persigue la obra. Primera idea, y citamos literalmente: la comuna utilitat deu precehir la singular, es 
decir, el bien común está por encima del particular. Segunda idea: que los guanys sien partits e que tots pusquen viure. Una idea tan avanzada, esta de repartir las ganancias, que a uno le cuesta admitir que se expresara en la Tarragona del siglo XV. En todo caso, esta noción fuerte del "bien común", que sin duda debe mucho al derecho en su formulación, pero que tiene su génesis en la experiencia de la vida en común, es lo que verdaderamente hace al ciudadano y la ciudad. Así lo decía Bartolo de Sassoferrato, que Juncosa también cita (pp. 266 y 270). Con las libertades alcanzadas, cónsules y consellers administran y defienden el bien común. El autor lo explica muy bien a través de las políticas municipales de atracción de pobladores y acceso a la ciudadanía, con el estímulo de la concesión de libertades y franquicias. Y también la vigilancia frente a la llegada de extraños.

El extenso capítulo dedicado a las elecciones municipales muestra que el sistema político, en el caso de Tarragona, es como un edificio de equilibrio inestable sometido a presiones opuestas y debilidades estructurales. Se trata de un capítulo en el que comparten protagonismo los tres actores de esta tesis, el rey, el arzobispo y los ciudadanos, cuyas acciones marcan la dinámica política en la ciudad. El rey y el arzobispo se enfrentaron por el control superior del gobierno municipal, sobre todo en los años 1373-1382, un duelo en el que los ciudadanos participaron no sabemos muy bien, al principio, si de grado o por fuerza. Pero participaron, y lo hicieron mayormente al lado del rey. Finalmente parece claro que la opción real acabó siendo voluntariamente la suya, quizá porque ofrecía a los ciudadanos mayor seguridad, más posibilidades de protagonismo en la vida pública y menos cargas, que la doble obediencia. Si la aspiración era sacudirse el señorío arzobispal y convertir Tarragona en una ciudad real exclusivamente, no lo conseguirían, aunque a los ciudadanos no les faltara decisión.

Los ciudadanos actuaban unidos frente al poder señorial, pero en realidad estaban divididos por la fortuna y la representación política, divisiones que se reflejaban en la composición del gobierno urbano, y que causaban tensiones, de ahí las sucesivas reformas del sistema electoral. Pero las tensiones sociales y políticas, que llegaron a degenerar en batallas callejeras entre ligas y bandos, fueron más que simples luchas por el gobierno municipal, fueron también la expresión violenta de las tensiones y desgarros sociales que la crisis bajomedieval producía. Una crisis a la que Juncosa y los documentos que aporta hacen no pocas referencias.

En resumen, el libro de Eduard Juncosa es duro por la densidad de las ideas e informaciones, pero fascinante por las problemáticas que desarrolla y estimulante por la metodología que aporta, en línea con las mejores investigaciones del hecho urbano medieval en Europa. Se trata, sin duda, del fruto maduro de una investigación amplia y profunda, que renueva y transforma nuestros conocimientos sobre la ciudad de Tarragona en la Edad Media. Pero lo más importante para las investigaciones futuras es que constituye un modelo sobre el funcionamiento de las complejas relaciones de poder en el marco urbano entre señores, y entre señores y ciudadanos.

JOSEP M. SALRACH Universitat Pompeu Fabra 
Sarah KAY, Parrots and nightingales: Troubadour quotations and the development of european poetry, Philadelphia, University of Pennsylvania Press, 2013, VIII+464 pp. ISBN 978-0-8122-4525-7.

L'assaig de Sarah Kay, Parrots and Nightingales. Troubadour Quotations and the Development of European Poetry (Philadelphia, University of Pennsylvania Press, 2013), a través de l'estudi de la pràctica de les cites líriques, ens ofereix una visió de conjunt de la recepció europea dels trobadors al llarg d'un ventall cronològic d'uns cent cinquanta anys, que va des del pioner de la tècnica, Raimon Vidal de Besalú fins a la cançó Lasso me, amb què, a parer de Kay, Petrarca expressaria simbòlicament la fi de la tradició de la cita, vinculada a la concepció dels trobadors com a mestres d'amor i poesia. Malgrat que les cites trobadoresques no són un fenomen literari inexplorat, la novetat del llibre rau en la diversitat d'àmbits geogràfics, lingüístics i literaris considerats i en la perspectiva comparada, que permet abordar el tema com un fenomen cultural complex.

Kay defineix aquest vast panorama a partir d'una dicotomia fonamental, que, a grans trets, enfronta, d'una banda, la modalitat de recepció pròpia del nord de França i de l'àrea germànica, on la gradual absorció de la poesia d'inspiració trobadoresca privilegia l'aspecte musical i emotiu de les composicions i les sotmet a una procés d'assimilació lingüística que desdibuixa la llengua originària; i, d'altra banda, la recepció característica de la regió occitanocatalana i de les cultures veïnes de l'àrea mediterrània septentrional, que es manifesta en el fenomen de la cita literal dels versos trobadorescos en la llengua originària i en la pèrdua del seu caràcter musical. En aquesta darrer cas, la fidelitat a l'original s'inscriu en un context escolàstic, de preservació acurada dels versos trobadorescos, contemplats no ja com a expressió del sentiment sinó com a canal de coneixement a través de la poesia. Kay designa metafòricament la primera de les dues modalitats de recepció assenyalades com a pròpia dels "rossinyols" (nightingales' way); i la segona, com a característica dels "papagais" (parrots' way), apel-lant al que connoten les característiques d'aquests dos ocells -un, cantaire; l'altre, capaç de "repetir" la veu humana-, així com a l'imaginari medieval d'aquestes aus que construeixen els exordis trobadorescos i textos narratius emparentats amb la tradició lírica, com ara les novas occitanocatalanes. Val a dir, en aquest sentit, que l'estudi de Kay es consagra bàsicament a l'anàlisi "dels papagais" dedicant tant sols la primera part del capítol 5 a il·lustrar el nightingales' way a partir del procediment de la inserció lírica practicat per Jean Renart a Guillaume de Dole, i a comparar-lo amb el mecanisme, en certa manera anàleg, de la cita lírica inaugurat per Raimon Vidal de Besalú. S'imposa d'aquesta manera una visió monolítica i falsament homogènia de la recepció dels trobadors occitans en contextos narratius francesos, que converteix una obra profundament original, com és Guillaume de Dole, en paradigma de referència; mentre que textos molt més influents en la narrativa posterior i més "característics" de la tradició francesa de les insercions líriques, com el Roman de la Violette de Gerbert de Montreuil, no s'esmenten en el cos del treball, tot i que, en apèndix es recullen els versos de trobadors occitans que apareixen en aquest roman. L'anàlisi de les cites en contextos catalans, occitans i italians és, però, acurada, notablement exhaustiva i clarament orientada a il·lustrar l'aspecte creatiu de la repetició. 
La impostació metodològica de partida s'assenta sobre els plantejaments psicoanalítics lacanians que l'autora trasllada a la teoria de Derrida sobre la repetició com a element generador d'inestabilitat simbòlica al voltant dels conceptes d'identitat i subjectivitat. La repetició és així contemplada com a motor del canvi, en el benentès que el nou context on s'insereix la cita canvia el significat d'allò que és repeteix així com la posició del subjecte que construeix o imagina el discurs citat, en un complex procés que implica trobador citat, citador i lector. Des d'aquesta perspectiva, l'autora atorga un important capital simbòlic a l'ús dels incipit com a forma abreujada d'introduir la citació: en l'incipit es materialitza la dialèctica entre el reconeixement i la ruptura que regeix el mecanisme de la cita lírica, en tant que element que permet la identificació de la composició, però que alhora convida to begin again: to initiate (even if one appears to repeat it) a symbolic realm (p. 20).

Adoptant una plantejament cronològic, l'estudi s'estructura en tres parts: la primera ("Pioneering Troubadour Quotation") dedicada als primers treballs on apareixen cites de trobadors, la segona ("Parrots and Nightingales"), a comparar la doble modalitat de recepció que dóna títol al llibre, i la tercera ("Transforming Troubadour Quotation"), a la transformació dels mecanismes de la cita lírica en obres dels segles XIII i XIV. Clou l'estudi un valuós conjunt de 17 apèndix que, recollint, sistematitzant i permetent la comparació de les cites trobadoresques localitzades en els diferents contextos que comenta el llibre (novas, romans, cançoners, composicions líriques...), ofereix als investigadors un tou de materials preciosos de cara a la prossecució de la recerca i al desenvolupament d'algunes de les intuïcions apuntades al llarg del treball.

La primera part del llibre comprèn quatre capítols, els dos primers dedicats a l'obra de Raimon Vidal, el tercer a las biografies trobadoresques d'Uc de Saint Circ, i el darrer als florilegia. El primer capítol serveix per il·lustrar un tret característic de la cultura occitanocatalana com és la producció de tractats gramaticals i poètics que equiparen la llengua vernacle al llatí i lend suport to the view of Occitan as somehow opening a pathway to rational understanding (p. 31). Aquest tractats pioners són situats en un precís context cultural a partir de l'estudi de la tipologia de les cites que incorporen (que es recullen en l'apèndix 3), de la nòmina de trobadors citats, de les implicacions de la funció modèlica atribuïda als trobadors, i de la tradició manuscrita, que suggereix una marcada i continuada permeabilitat entre Catalunya i Itàlia. El segon capítol es dedica a les novas on, a diferència dels tractats gramaticals, que concentren l'atenció en l'aspecte lingüístic, les cites esdevenen arguments d'autoritat en boca dels personatges i ens situen així davant d'un mecanisme de citació que, focalitzant l'atenció en el contingut, teixeix un nou vincle entre cita, memòria i coneixement. Mentre que en la primera part del capítol Kay recull i sistematitza dades conegudes, més original i interessant resulta l'anàlisi de la tècnica de citació de les novas de Raimon Vidal que fa a partir del comentari de tres cites concretes, extretes de $B E d T 242.55, B E d T 406.42$ i $B E d T$ 80.38. Kay mostra com en aquests tres casos la interpretació del text de Raimon Vidal exigeix el coneixement de les composicions senceres de les quals han estat extrets els fragments citats. La cita, the tip of an iceberg of unacknowledged debt (p. 48), funciona així com a clau de lectura que revela les fonts líriques del relat i apel·la al coneixement per part del públic de les parts no citades de les cançons donant lloc a una intrincate web of intersubjective interactions 
in the course of which knowledge is remembered, forgotten, affirmed, disavowed, assimilated, displaced, produced, or found waiting (pp. 52-53).

El capítol consagrat a Vidas i Razos comença amb un clarificador repàs a qüestions ja ben establertes per la crítica, com ara el context en què se situa aquesta modalitat de recepció trobadoresca, marcat pel pas de l'oralitat a l'escriptura, en concomitància amb l'elaboració dels cançoners, o les seves connexions amb la forma escolàstica del comentari. La diferència entre els mecanismes de cita en Vidas i en Razos, l'il·lustra un estudi dels cançoners vènets $I$ i $K$, que contempla la tipologia $\mathrm{i}$ frequiència de les cites, la seva ubicació, funció i extensió, així com la relació de trobadors citats. Una atenció particular concedeix l'autora a la funció que, com a element estructurant de la compilació, desenvolupa la cita incipitaria, introduïda per Raimon Vidal en las Razos i indicadora de l'inici d'una nova fase en la recepció dels trobadors. El capítol que tanca aquest primer bloc es dedica a un conjunt de florilegia, ( Dc Fa Cm H G J), on els versos trobadorescos, recollits en l'apèndix 2, són compilats per a esdevenir futures cites. L'autora posa de relleu l'alt nombre de materials compartits entre aquests florilegis de procedència italiana i els textos catalans i occitans del segle XIII i analitza les implicacions de les diverses maneres de presentar les cobles seleccionades: intruïdes per l'incipit de la composició ( $\mathrm{DcF} F \mathrm{Cm}$ ); reduïdes a l'incipit i introduïdes per rúbriques en prosa que expliciten els possibles contextos de la citació $(H)$; presentades com un conjunt d'esparsas anònimes $(G J) \ldots$ Malgrat aquesta diversitat, Kay fa notar com en tots els casos el context transforma l'estatut dels versos citats, que deixen de ser l'expressió de sentiments individuals per esdevenir reflexions genèriques, que hom convida a usar amb marcada llibertat i flexibilitat. Paradoxalment, la pràctica de la cita literal obre així el camí de la transformació i del canvi, fent-se evident que Anthologization is not a mode of confinament but a means of releasing the textual subject from entrapment in its original context (p. 87).

La segona part de l'obra es dedica a contrastar el nightingales' way i el parrots' way a partir de la comparació entre la tècnica de la inserció lírica practicada per Jean Renart en Guillaume de Dole, obra, per a Kay, emblemàtica de la primera modalitat, i Las novas del papagai, que il·lustren la recepció escolàstica dels trobadors pròpia de la tradició occitanocatalana. La tècnica de Jean Renart, definida pel caràcter musical i per la diversitat genèrica de les composicions líriques, així com per la francesització lingüística de les tres peces occitanes que incorpora el roman, és interpretada per Kay no tant en termes d'innovació com de reacció a la pràctica occitanocatalana de la cita. Per a l'autora, les insercions, mal integrades en el context narratiu tant en el pla formal $^{1}$ com semàntic, funcionarien com a mers marcadors d'intensitat emocional en determinats moments del relat, mentre que la pàtina lingüística francesa i la presumpta marginalitat de les composicions occitanes s'explicarien, en un context històric marcat per la croada càtara i per l'expansió de la França de Felip August, com una manio-

\footnotetext{
${ }^{1}$ Recordem que en l'obra de Jean Renart ja es detecta un ús conscient de la rima com a mecanisme d'integració formal, que es generalitzarà en els successius romans amb insercions líriques. Vegeu, en aquest sentit, Carla Battelli, Testo lirico e contesto romanzesco. Sondaggi sulla tradizione del romanzo a citazione, dins Hilty Gerold (coord.), Francia tra 1200 e 1250. Actes du XXe Congrès International de Linguistique et Philologie Romanes, Université de Zürich (611 avril 1992), Tubinga, Basel-A. Franke, 1993, vol.V, pp. 181-195.
} 
bra orientada a la reclassificació de l'occità com a dilecte francès i al desmantellament i desprestigi de la poètica trobadoresca eclipsada pel lirisme més genuïnament francès de la cançó de dona, de la qual el roman dóna diverses mostres. El caràcter secundari i prescindible del contingut de les cançons, que Kay atribueix a les insercions líriques de Guillaume de Dole, és especialment marcat, per a l'autora, en els tres exemples de cançons occitanes que trobem al roman (p. 96). Aquesta afirmació, però, no passa per un estudi exhaustiu del context narratiu, anàleg al dut a terme en el cas de las novas de Raimon Vidal. Un estudi d'aquestes característiques no només hauria qüestionat l'afirmació sinó que hauria revelat interessants coincidències, com ara la importància atorgada a les parts no citades de les insercions líriques, que també en l'obra de Jean Renart, i després en la de Gerbert de Montreuil, desenvolupen una funció hermenèutica i posen en joc la competència literària del públic ${ }^{2}$. Per part nostra, lluny d'acceptar aquesta marginalitat de les composicions occitanes, hem mantingut la tesi contrària en un article recent on, defensant que constitueixen l'autèntica matriu lírica del relat, hem analitzat com l'acurat procés d'integració d'aquestes tres peces en el nou context narratiu aboca a una resemantització del lèxic de la fin'amors per adaptar-lo a la ideologia vehiculada pel roman, que recondueix l'ideal amorós trobadoresc a l'ètica monàrquica i matrimonialista pròpia de la tradició narrativa d'oül ${ }^{3}$. Tot i convenir amb Kay que Jean Renart opera una assimilació de l'ideal trobadoresc en clau cultural i política francesa, discrepem en la fesomia concreta que revesteix aquest procés d'assimilació, però sobretot en el fet que el contingut de les cançons no hi tingui cap mena de pertinença. No només els nostres estudis, també els de molts altres investigadors, com ara M. Zink, E. Baumgartner o M.R. Jung, han posat de manifest, amb matisos diferents, fins a quin punt la complexa xarxa de relacions intertextuals que generen les insercions líriques tradueix la ideologia canalitzada pel roman. I, sobretot, no oblidem que és el mateix Jean Renart, qui, al pròleg del roman, apunta no tant a la música com al contingut de les cançons en reptar el seu públic a descobrir en quina mesura totz les moz des chans convenen als del conte i presumeix que és aquesta una adequació prou subtil, atès que vilains nel porroit savoir.

Las novas del papagai, on a més a més l'ocell desenvolupa un paper protagònic, il·lustren the parrots' way. Kay estudia la transmissió manuscrita de les diferents versions que ens han arribat del text, no des d'una òptica cronològica orientada a reconstruir un presumpte original sinó des d'una perspectiva geogràfica, amb la intenció de copsar les variants d'aquesta segona modalitat de recepció trobadoresca, característica d'un arc territorial que va des de Catalunya al nord d'Itàlia passant per Occitània. Des d'aquest principi metodològic, la tradició textual, les diferents versions de la història i sobretot el paper atribuït al papagai, en qui s'encarna la força modelitzadora del desig que hom atribueix a la llengua occitana, aparegui o no la cita explícita, posen de manifest el marcat multilingüisme d'aquesta àrea geogràfica definida per la còpia, la conservació i l'ús de l'occità en la transmissió trobadoresca.

\footnotetext{
${ }^{2}$ Vegeu Meritxell Simó, La arquitectura del roman courtois con inserciones líricas, BernaBerlín-Francfort-Nova York-París-Viena, Peter Lang, 1999.

${ }^{3}$ Vegeu Meritxell Simó, Traducció i reescriptura de la canso occitana en el Roman de la Rose de Jean Renart, "Anuario de Estudios Medievales" 45/1 (2015), pp. 79-107.
} 
La tercera part del llibre comprèn cinc capítols, on s'analitza la transformació de les estratègies de citació en dos tractats poètics (el De vulgari eloquentia de Dante al capítol 9 i les Leys d'amors de Guilhem Molinier al capítol 10) i s'exploren nous contextos de cita com ara les composicions líriques (als capítol 7 i 11) i obres de caràcter enciclopèdic i moralitzant que fan dialogar la poesia amorosa dels trobadors amb l'amor diví (el Breviari d'amor de Matfre Ermengau, al capítol 8, y la Divina Commedia, al capítol 9). El que comparteixen tots aquests textos és la percepció dels trobadors ja no com a autoritats i font de coneixement per als contemporanis sinó com a punt de partença per a la creació de noves formes de coneixement i d'expressió poètica en els nous parlars vernacles.

Als contextos lírics es dedica el primer capítol, centrat en la confrontació entre $B E d T 74,9$, on Bartolomé Zorzi pren la primera meitat de cada cobla d'una composició de Peire Vidal $(B E d T$ 364, 39) i $(B E d T$ 304, 1), on Jofre de Foixà clou cada cobla amb l'incipit d'una composició trobadoresca, seguint el model fornit pel trouvère Gilles de Viés-Maisons. Kay explora aquest antecedent i altres connexions amb la lírica dels trouvères per concloure que mentre que la pràctica de Zorzi does not question the parrot's way (p. 135), la reinserció de la cita lírica en l'àmbit de la cançó per part de Jofre reconnects the parrot's way to that of the nightingales' way in a playful but aso significant renewal of the earlier Occitano-Catalano-Italian practice (p. 134).

El Breviari d'Amor de Matfre Ermengau, vasta enciclopèdia consagrada a plasmar la doctrina de l'amor diví com a principi creador i ordenador de l'univers, marca un punt àlgid en l'ús de la cita com a mecanisme de canvi en la relació entre desig i coneixement. Inserint les cites líriques en un context filosòfic orientat pel paradigma Caiguda-Redempció, Matfre rehabilita la lírica trobadoresca convertint-la en font privilegiada de regeneració moral a través de comentaris, omissions, reescriptures i tries insospitades que forcen una lectura salvífica dels versos occitans i avien al lector pel camí de la redempció. Kay analitza amb detall aquests procediments i posant de manifest analogies amb Dante, coincidències amb els florilegia GJ i molt especialment amb $H$, postula que, malgrat ser una obra redactada en Occitània per a un públic occità, la transformació en l'ús de la cita que el Breviari representa podria haver-se iniciat en un context cultural més ampli.

Cal destacar la novetat del plantejament del capítol dedicat a Dante, que per primera vegada aborda la relació entre el poeta florentí i els trobadors a la llum de la tradició de cita i comentari trobadorescos analitzada al llarg del llibre. Adoptant la noció d'ex-aproppiation, introduïda per Derrida, Kay mostra com la inserció del De vulgari eloquentiae en la traïció gramaticopoètica occitana no té altra finalitat que, tot i reconeixent el prestigi dels trobadors, relegar-los al passat i convertir-los en un pas intermedi en el procés de regeneració teològica i política de la llengua poètica que culminarà Dante. Distingint la variació lingüística no només en l'espai, com els seus antecessors, sinó també en el temps, Dante converteix la lògica de la regeneració, inscrita en la mateixa trajectòria teològica dissenyada per Matfre, en una lògica de la substitució, que duu a reemplaçar l'occità per l'italià. En la Commedia, Dante no es preocupa tant de col-locar trobadors en el passat com de regenerar el seu desig, maniobra que no s'acompleix, com en el cas de Matfre, a través del comentari que introdueix la cita reinterpretant-la, sinó que dóna lloc a una sofisticada reescriptura 
dels versos trobadorescos. Kay il·lustra el procediment amb la representació d'Arnaut Daniel al text dantesc, posant de relleu la complexa xarxa de relacions intertextuals en què s'inscriu la referència a BEdT 29.10 que apareix al cant 26 del Purgatori, així com l'estratègia de Dante, que reemplaçant la cita en boca d'Arnaut per uns versos penitencials, desplaça la reescriptura dels adynata de la cèlebre tornada als versos inicials del Purgatori, un espai que el trobador ja ha deixat enrere.

Finalment, Les leys d'amor i la cançó Lasso me de Petraca clouen l'estudi com a mostra de la utilització de les cites en clau d'obertura a la renovació poètica. Kay estudia la reinvenció de la poesia occitana per part de Molinier, que la recondueix cap a l'esfera pública convertint-la en instrument de promoció de valors cívics i morals, a través del comentari de les fonts italianes utilitzades per l'autor, com Brunetto Latini i Albertano da Brescia, i de les estratègies de cita que apareixen en les successives redaccions de les Leys: des de la confecció de cites ad hoc i l'eliminació dels trobadors clàssics en benefici dels contemporanis, a l'afirmació d'un cànon reduït al propi Molinier i a At de Mons, trobador al que hom atorga la funció de pont entre la vella poètica i la nova escola.

Aquesta superació de la tradició representada en els trobadors clàssics que il·lustra la cita en les Leys és el punt de partença de Lasso me de Petrarca, l'exemple aportat per Kay que millor il·lustra la concepció de la repetició com a motor de canvi i de renovació que havia formulat com a hipòtesi de treball a la introducció. En Lasso me, Petrarca, reprenent el model formal de Jofre de Foixà, comentat en el capítol 7 , clou cada estrofa amb l'incipit d'una composició lírica. Només la primera de les cites, Dreitz e raizon quieu chant em demori (BEdT 233.4), correspon a un trobador occità, mentre que les altres corresponen a poetes toscans més o menys contemporanis de l'autor. Segons Kay, la finalitat de Lasso me seria posar fi a la cita de versos trobadorescos, construint la percepció d'una cesura temporal que ubica irreversiblement aquesta tradició en el passat. La fina anàlisi que duu a terme Kay de la composició mostra com el diferent estatut de la cita trobadoresca, tant en el pla lingüístic com en el pla semàntic, inserida en el recorregut, de l'amor humà a l'aspiració to understand the beauty of creation (p. 193), que dissenya la cançó, reforça la idea de trencament respecte a l'univers trobadoresc inaugurant the desire to desire differently, and to desire new forms of knowledge (p. 194). La controvertida atribució de la composició, que Petrarca podria haver associat a Arnaut Daniel, és presentada per Kay com un element constitutiu de la cita, ja que la desvinculació de la subjectivitat trobadoresca a què condueix l'estratègia compositiva exigeix començar la genealogia poètica que traça la cançó no amb un trobador celebrat al qual poder reemplaçar but with a figure so espectral and uncertain as to provide no firm anchorage (p. 195).

Clou l'assaig un breu apartat de conclusions que reorganitzen de forma clarificadora les principals idees disseminades al llarg de l'estudi aviant-les cap a la formulació d'una tesi: la modalitat de recepció designada com a parrots' way s'hauria revelat la més productiva en tant que principi de canvi i de renovació poètica. La defensa d'aquesta tesi probablement exigiria una anàlisi més exhaustiva del nightingales'way que el dut a terme en el capítol consagrat a Jean Renart. Com ja hem fet notar en el cos d'aquesta exposició, l'estudi de la tradició francesa revelaria no pocs punts d'intersecció que obligarien a matisar la neta dicotomia que traça el llibre com a hipòtesi de partença, i, en el marc de la dialèctica entre unitat i diversitat que 
caracteritza la Romania medieval, és ben probable que aquestes semblances ens ajudessin a copsar millor les idiosincràsies de cada tradició. També en l'àmbit de la tradició occitanocatalana, a la que l'autora dedica principalment la seva atenció, la pràctica de la cita lírica va produir textos que no són contemplats en l'estudi, com no podria ser d'altra manera, atesa la vastitud de l'arc cronològic i geogràfic considerat. El treball de Kay, però, i els preciosos materials que recopila en apèndix ofereixen un punt de partença immillorable per ubicar aquests textos en un escaquer complex i abordar-los des de la perspectiva metodològica que considerem l'adequada. Pensem en aquest sentit que el principal mèrit d'aquest assaig, exhaustiu, rigorós, complex i ben documentat és el d'inaugurar una nova i fructífera direcció en l'estudi dels textos medievals amb cites líriques, que habitualment havien estat abordats des d'una perspectiva monolingüe i circumscrita a una única tradició textual (gèneres lírics, roman, preceptives poètiques...).

MERITXELL SIMÓ

Universitat de Barcelona - IRCVM

Jean-Michel Minovez, Catherine Verna, Liliane Hilaire-PÉrez (dirs.), Les industries rurales dans l'Europe médiévale et moderne, Toulouse, Presses Universitaires du Mirail, 2013, 312 pp. ISBN 978-2-8107-0274-9.

La edición número 33 de las jornadas de la abadía de Flaran abordó la problemática del desarrollo de la industria en ámbitos rurales de Europa durante el período anterior a la revolución industrial, reuniendo a medievalistas y modernistas de diversos países, entre los que figuran tres españoles, cuyas contribuciones son objeto de publicación en el presente libro. Se trata sin duda de una cuestión de importancia central para la historiografía europea, que ha dado lugar a una abundante producción en forma de monografías de carácter local y regional, y también ha propiciado debates académicos en los que se manejó con profusión el concepto de protoindustrialización, y otros tales como Kaufsystem, Verlagsystem, difundidos por la historiografía alemana, con Kriedte a la cabeza, y putting-out system, acuñado por la historiografía anglosajona. En esta ocasión este singular fenómeno del desarrollo de regiones en las que se produjo una evidente concentración de actividades industriales en los siglos bajomedievales y modernos, vuelve a ser objeto de valoración mediante una profundización en el análisis de varios ejemplos regionales concretos, tomados de muy diversos ámbitos de Europa. Y, como corresponde a una visión actualizada del problema, se incide en especial en el análisis de aspectos novedosos, poco tenidos en cuenta en los estudios más clásicos, tales como la caracterización de la figura de los empresarios, la valoración del papel de la pluriactividad entre el campesinado o el análisis de la comercialización de los productos manufacturados en el campo, no sólo cuando eran destinados a la exportación a larga distancia, el aspecto más atendido por los autores clásicos, sino también cuando se destinaban a satisfacer la demanda de productos de consumo básico de la población local de bajo nivel socioeconómico, vertiente del fenómeno ignorada por los investigadores hasta fechas recientes. 
Como es habitual en las jornadas de Flaran, el período cronológico tomado en consideración es muy amplio, pues abarca los siglos medievales y modernos, pero, salvando unas pocas excepciones, los trabajos reunidos se especializan al circunscribirse a alguno de los dos períodos, quedando así reflejada la importante cesura que en el ámbito académico todavía separa a los medievalistas de los modernistas, incluso a los que se interesan por la historia económica, que deberían ser más proclives a percibir la continuidad entre los dos períodos. Desde la perspectiva de la problemática abordada en este libro esta fragmentación de la investigación en departamentos estancos, definidos por criterios cronológicos, resulta aún más difícil de justificar, aunque no deje de resultar comprensible por las exigencias que impone el trabajo con la documentación. Sea como fuere, y dado el carácter de la revista en la que publicamos esta reseña, nos limitaremos aquí a dar breve cuenta de los trabajos que aluden al período medieval, ignorando los que se centran exclusivamente en los siglos modernos, que representan más de la mitad del total.

Por su carácter general y su atención preferente a las cuestiones teóricas, conceptuales y metodológicas cabe tomar en consideración conjuntamente las dos primeras contribuciones, a cargo de los tres editores del libro, la primera, y de Mathieu Arnoux la segunda. Los editores plantean en su breve introducción consideraciones conceptuales de carácter general y proponen cuatro grandes puntos para profundizar en su tratamiento: los territorios industriales, la pluriactividad, los empresarios, y la circulación y consumo de la producción. Mathieu Arnaux, por su parte, reflexiona sobre la problemática de la aparición de las regiones industriales en Europa, en virtud de un proceso de especialización económica regional, llamando la atención sobre la necesidad de enfocar su análisis, para explicar la concentración de la fabricación de productos en determinadas zonas rurales, desde dos perspectivas complementarias, la de la demanda, por un lado, y la de la oferta, por otro.

La serie de ejemplos regionales se inicia con un trabajo de Andrea Berlucchi sobre el desarrollo de la manufactura de paños de lana en el espacio rural sometido a la jurisdicción de la ciudad de Florencia, durante el período medieval. Destaca entre sus conclusiones la constatación de que esta actividad experimentó un mayor florecimiento durante el siglo XIII, para decaer en las siguientes centurias, como consecuencia, entre otras causas, de la prohibición que impuso la ciudad a la población campesina asentada en su territorio de fabricar paños de paños de calidad mediana, y de utilizar otra materia prima que no fuesen las lanas bastas de producción local.

Christopher Dyer nos ofrece un apretado panorama sintético sobre la implantación de la actividad industrial en los ámbitos rurales de la Inglaterra bajomedieval y altomoderna. Demuestra que alcanzó notable importancia hasta el punto de que pudo haber proporcionado ocupación a alrededor de un quinto del total de la población campesina. Identifica las comarcas en que alcanzó mayor desarrollo, defendiendo un punto de vista matizado, pues, sin dejar de reconocer que las zonas de montaña y boscosas, menos aptas para el cultivo del cereal, fueron aquéllas en que su población dependió en mayor medida de su dedicación a actividades industriales, éstas tampoco resultaron irrelevantes en otras comarcas más aptas para la cerealicultura. Plantea interesantes reflexiones sobre el papel desempeñado por los empresarios en el desarrollo de las industrias rurales, y sobre todo insiste en recordar que su producción estuvo muy diversificada, y se destinó a muy diversos mercados, pues mientras 
que una parte fue objeto de exportación, como es el caso emblemático del estaño de Cornualles y Devon o de ciertos paños, otra parte mucho más importante se orientó a satisfacer la demanda de los sectores más humildes de la población local.

Siguen a continuación tres trabajos dedicados a los reinos hispanos medievales. En concreto Íñigo Mungueta Moreno informa sobre el desarrollo de la actividad siderúrgica en las provincias vascas y Navarra durante el Medievo. Germán Navarro Espinach, por su parte, ofrece un panorama global sobre el desarrollo de la manufactura textil en los reinos de Aragón y Valencia durante los siglos XV y XVI, identificando las principales comarcas productoras, de modo que en rigor no sólo informa sobre la manufactura que se desarrolla en zonas rurales, sino también sobre las manufacturas urbanas, de grandes ciudades como Valencia o Zaragoza, y de otros muchos núcleos de segundo rango. Basándose en los resultados de investigaciones propias, y de las de otros varios jóvenes investigadores procedentes en su mayoría de la Universidad de Valencia, aporta informaciones de gran interés para la caracterización de la manufactura textil aragonesa y valenciana de la baja Edad Media y la temprana Edad Moderna, entre las que destacaríamos, por ejemplo, las relativas al papel clave que como "empresarios" habrían desempeñado los pelaires. Por fin, Catherine Verna dedica su atención a la comarca del Vallespir, que, aunque en la actualidad pertenece a Francia, durante el Medievo formó parte de la Corona de Aragón. Aprovechando la información proporcionada por documentación notarial de esta comarca de los siglos XIV y XV, realiza una novedosa propuesta metodológica para profundizar en el estudio de las industrias rurales desde la perspectiva de la caracterización de los empresarios mediante la reconstrucción de sus biografías. Y nos ofrece en concreto las de dos individuos, caracterizados como empresarios rurales en el ramo de la metalurgia, aunque también dedicados al mismo tiempo a otras actividades.

Mohamed Ouerfelli, por su parte, analiza la actividad de la fabricación de azúcar en Sicilia durante el siglo XV, llamando la atención sobre la fuerte implicación del capital mercantil, preferentemente de origen foráneo, en su promoción, que, no obstante, no resultó muy exitosa a largo plazo por la fuerte competencia que pronto le comenzó a hacer el cultivo de la caña en azúcar por mano de obra esclava en territorios coloniales del Atlántico. Y, por fin, Jean-Marie Yante da cuenta del desarrollo de la industria metalúrgica en la región entre el Mosa y el Mosela, que hoy se reparten varios estados de la Unión Europea, durante los siglos XIV, XV y XVI, prestando particular atención a aspectos tales como la caracterización de los empresarios que la promovieron o la identificación de sus principales vías de financiación.

Dado que el resto de contribuciones se centran exclusivamente en diversos momentos de la Edad Moderna, vamos a prescindir de dar aquí noticia de ellas. Como valoración de conjunto señalaremos que se trata de un libro de contenido muy heterogéneo, pese a que los autores se esfuerzan por tratar de dar respuesta a una serie de cuestiones comunes, que les habían sido inicialmente propuestas por los organizadores y son explicitadas en la introducción. Pero lo hacen de forma muy diferente unos de otros, pues algunos nos ofrecen amplias panorámicas de obligado carácter sintético sobre extensos y complejos territorios, que abarcan uno o incluso varios reinos, mientras que otros se circunscriben al microanálisis de casos singulares, en ocasiones de marcado carácter local. El libro es, no obstante, de obligada lectura para los interesados en la historia socioeconómica de Europa, tanto por razón de la 
abundante y diversa información inédita que proporciona, como por su utilidad como guía para adentrarse por los nuevos caminos abiertos por las líneas de investigación más innovadoras en curso en las universidades europeas.

Máximo Diago HeRnANDo Instituto de Historia, CSIC. Madrid

María Adelaide Miranda, Alicia Miguélez CAVero (eds.), Portuguese studies on medieval illuminated manuscripts, Madrid - Barcelona, Fédération Internationale des Instituts d'Etudes Médiévales, 2014, XV+194 pp. (Textes et Études du Moyen Âge; 76). ISBN 978-2-503-55473-0.

Si bien es cierto que en las últimas dos décadas las nuevas tecnologías han propiciado el desarrollo de los estudios sobre iconografía en códices medievales, también es preciso admitir que, incluso a escala global, todavía queda mucho por hacer. La situación es más acuciante, si cabe, en el caso de Portugal, donde -como bien nos recuerda P. Stirnemann- el terremoto de 1755 destruyó una ingente cantidad del patrimonio archivístico y cultural de la Edad Media (p. VII). De esta manera, el presente volumen se ha concebido como un espacio donde presentar los resultados de las últimas investigaciones en el campo a manos de un naciente grupo de jóvenes investigadores.

El volumen se compone de ocho artículos firmados por trece investigadores distintos. Son frecuentes las colaboraciones (en ocasiones un artículo viene firmado por tres, o incluso cinco autores) y algunos firman más de uno (M.J. Melo cuenta, por ejemplo, con tres entradas), aspecto que responde a la multiplicidad de puntos de vista desde los que se ha llevado a cabo el análisis de los manuscritos. Así se pone de manifiesto en el penúltimo de los artículos cuando se afirma que l'interdisciplinarité de l'équipe, qui mène ce projet, avec des chercheurs des sciences sociales et humaines et des sciences, a éte fondamentale dans ce cas ci à l'étude (p. 149), afirmación que, no obstante, podría aplicarse a casi todas las colaboraciones incluidas en el volumen. El vínculo de todos los artículos es, obviamente, el estudio de las miniaturas en los códices medievales portugueses, aunque el tema y la metodología empleada varían considerablemente de uno a otro. La mayoría versa sobre el programa iconográfico de una obra específica, como por ejemplo el Comentario al Apocalipsis -Beatocompuesto en el monasterio de São Mamede de Lorvão a finales del siglo XII, el Compendium theologicae veritatis copiado en el monasterio de Alcobaça en 1332, una copia de principios del XIV de las Decretales de Gregorio IX qui n'a jamais été l'objet d'aucune étude (p. 82) o dos libros de horas del siglo XV conservados en la Biblioteca Nacional de Portugal.

Distinto acercamiento es el de L. Campos Ribeiro, quien analiza el motivo iconográfico (o simplificación iconográfica del sistema astrológico) conocido como "los hijos de los planetas" en varios manuscritos del siglo XV, o el de L. Afonso y T. Moita, quienes, en el último artículo del volumen, nos ofrecen un extensivo estudio de veintiséis manuscritos hebreos portugueses conservados hoy en bibliotecas de medio mundo. Por último, y para resaltar el carácter interdisciplinario del volumen, cabe destacar que los dos primeros artículos están estrechamente conectados entre sí. 
En el primero se analiza detalladamente la paleta de colores utilizada en los monasterios de Santa María de Alcobaça, São Mamede de Lorvão y Santa Cruz de Coimbra, lo que ha llevado a las autoras a concluir que en los siglos XII y XIII los monasterios portugueses utilizaban un determinado "sistema de colores" con fines muy específicos. De la misma manera, en el segundo artículo se aplican las conclusiones del primero para analizar tres copias del tratado de Hugues de Fouilloy, De avibus, conservadas en los tres monasterios anteriormente citados, con lo que ambos se complementan perfectamente.

Poco hay que objetar, pues, a un volumen tan interesante y lleno de posibilidades. El texto es, por lo general, correcto, y se incluye un "Índice de manuscritos" que resulta de gran utilidad, además de treinta y dos ilustraciones a color y siete en blanco y negro que acompañan a los artículos. Sin embargo, el hecho de que se recojan aquí artículos firmados por varios autores provoca, en ocasiones, que la coherencia interna del volumen se debilite. Así, por ejemplo, cuatro de los artículos están escritos en francés, a pesar de que el volumen se haya concebido en lengua inglesa. El título, el prefacio, la introducción, la lista de autores, los restantes cuatro artículos y los dos índices incluidos al final están escritos en inglés, con lo que quizás hubiera sido deseable que los cuatro artículos en minoría se hubieran traducido a esta lengua. De manera más importante, el libro no tiene ni índice onomástico ni toponímico, y el (breve) "Índice de autores clásicos y medievales" al final del volumen no es de mucha utilidad, ya que las entradas no recogen de manera fidedigna el texto de los artículos. Por ejemplo, a pesar de que Hugues de Fouilloy se cita varias veces en las páginas 3233, y de que Raimundo de Peñafort, Bernard de Parme y Gregorio IX vienen citados en la página 81 , ninguna de estas entradas -por citar únicamente algunos casos- ha quedado recogida en el índice.

En definitiva, y a pesar de las obvias dificultades que el análisis del patrimonio cultural portugués plantea, es grato comprobar que existe un grupo de investigadores consagrados al estudio de las miniaturas e ilustraciones de los códices portugueses, tarea fundamental y complementaria a la de otras iniciativas similares como la creación de la base de datos Imago, cuyo objetivo principal es el de catalogar el patrimonio iconográfico portugués que ha llegado a nuestros días en esculturas y manuscritos de la Edad Media. Como bien nos recuerda una de las editoras del volumen, en Portugal el desarrollo de los estudios sobre manuscritos medievales iluminados ha sido breve pero intenso ( $\mathrm{p}$. IX). Las aportaciones recogidas en este volumen son buena prueba de la seriedad y compromiso de esta nueva generación de investigadores.

DAVID ARBESÚ

University of South Florida

Pádraig P. Ó NÉILl (ed.), Psalterium Suthantoniense, Turnhout, Brepols 2012, 456 pp. (Corpus Christianorum. Continuatio Mediaevalis; 240). ISBN 978-2503-53601-9.

La signatura MS C.9 de la biblioteca del St John's College de Cambridge corresponde a un ms. (H) que contiene una copia glosada del Salterio con algunas notas en irlandés antiguo. La edición crítica preparada por P.P. Ó Néill va precedida 
por un estudio preliminar muy completo. En la introducción propiamente dicha, que constituye el primer capítulo del preliminar, una primera parte se dedica a la historia, la descripción externa del ms., su contenido, datación y lugar de origen; en la segunda, se describen los textos principales que transmite: salmos, collectae y cantica, y, en la tercera, los textos ancilares o subsidiarios: argumenta y glosas.

Sobre la historia de $\mathrm{H}$ nada sabemos hasta que aparece en el catálogo de la biblioteca del St Martin's Priory en Dover, de 1389. En 1534, con la disolución del priorato, pasó a manos privadas y hacia 1615 fue adquirido por H. Wriothesley (15731624), primer conde de Southampton; finalmente, en 1635, llegó al St John's College.

Desde el punto de vista paleográfico, se diferencian tres tipos de letra: en los textos principales, semiuncial insular en el texto de los salmos, los cantica y la primera collecta, una minúscula insular híbrida en las restantes collectae y los tituli, $\mathrm{y}$, en los textos ancilares, los argumenta y las glosas, una minúscula insular tardía. Son identificables cuatro o incluso cinco copistas, que actuaron sucesivamente en el ms. A partir del análisis de sus respectivas intervenciones en el proceso de copia el editor concluye que los tres textos principales (salmos, collectae y cantica) así como los tituli de cada salmo fueron copiados de un mismo salterio. Por su parte, los argumenta y las glosas fueron incorporadas al mismo tiempo, lo cual sugiere que proceden de una fuente común, pero distinta del salterio que sirvió de modelo para los textos principales; determinadas características que comparten los argumenta y algunas de las glosas más largas llevan a pensar en un comentario como fuente de ambos. H es uno de los mss. irlandeses iluminados más elegante y mejor conservado del período pre-normando. Contiene tres iluminaciones, que ocupan sendas páginas, a modo de portada de cada una de las tres secciones de cincuenta salmos en que se divide el salterio. El inicio de salmo se indica con una capital decorada y el de verso con una capital coloreada. En lo referente a la ortografía, en las pp. XXX-XXXII se ofrece una relación de las desviaciones ortográficas que se observan en $\mathrm{H}$, seguida de una discusión en que se recoge la opinión de Harvey sobre las particularidades ortográficas de los textos latinos en ámbitos de habla celta. En opinión del editor (pp. XXXIV-XXXV), $\mathrm{H}$ es un códice que no se concibió en un principio para la finalidad que acabó por tener, esto es, un salterio para uso escolar. El tipo de letra y la ornamentación sitúan la fecha de composición entre finales del s. X y comienzos del XI. El lugar resulta más difícil de precisar. Como indicios de una posible relación de $\mathrm{H}$ con el norte de Irlanda se pueden aducir algunas evidencias: las variantes del texto gallicanus de H se corresponden con las que presenta V (MS Lat. 12910 de la Biblioteca Vaticana), un salterio escrito en el norte de Irlanda a finales del s. XI; también el texto de los cantica 1 y 7 es muy cercano a la versión que transmite el Antifonario de Bangor o, en fin, la mención en una glosa de $\mathrm{H}$ de dos santos no irlandeses, Pedro y Martín de Tours, que gozaron de un culto especial en Armagh.

El texto bíblico es el del Psalterium Gallicanum, versión latina de Jerónimo a partir de los LXX, usual en el ámbito gaélico medieval; la notable coincidencia de las variantes de $\mathrm{H}$ con las que aparecen en $\mathrm{V}$, salterio que representa un escalón avanzado en el desarrollo de la familia irlandesa del Gallicanum, permite considerar a $\mathrm{H}$ como texto gallicanus irlandés tardío. Las collectae u orationes y los cantica al final de cada sección de cincuenta salmos (tres, tres y uno, respectivamente) son característicos de los salterios irlandeses; las primeras son series de cinco octosílabos rimados, 
formato propiamente irlandés, los segundos están tomados del Antiguo Testamento; los cantica 1, 5 y 6 son todavía texto uetus, el resto, Vulgata. Los tituli, al comienzo de cada salmo, cuyo origen se remonta al salterio hebraico, ofrecen información sobre la autoría, circunstancias de composición, acompañamiento musical y uso litúrgico; las variantes que presentan los tituli de $\mathrm{H}$ coinciden con las que aparecen en la familia irlandesa del Gallicanum.

En el margen superior derecho o izquierdo, cerca del comienzo del salmo, aparece el argumentum, cuya fuente principal, en el caso de H, es la obra del pseudoBeda, Argumenta in psalmos (PS-BED Arg); el argumentum consiste en tres breves interpretaciones, en ocasiones dos, para cada salmo: la primera recoge la exégesis literal-histórica de la escuela de Antioquía según la versión latina de Julián de Eclano del comentario sobre los salmos de Teodoro de Mopsuetia (IUL Ps), la segunda es de carácter alegórico y cristológico, y la tercera, moral y alegórico; esta última está tomada en ocasiones de los comentarios de Jerónimo (HI Ps) y de Arnobio (AR Ps); el copista que introduce los argumenta en $\mathrm{H}$ a menudo acorta o sintetiza el texto de la fuente por necesidades de espacio. Dada la colocación preminente de los argumenta, sería de esperar que su influencia en la glosa interlineal fuera dominante, no obstante, salvo algunas excepciones, la línea interpretativa de esta discrepa de la propuesta en el argumentum, en especial, en lo que atañe a las interpretaciones históricas.

El texto del salterio de $\mathrm{H}$ está glosado. Se distinguen dos estratos de glosas: un primer estrato, que comprende todo el texto, a excepción de los salmos 96 al 100, y un segundo estrato, algo posterior, que se limita a los salmos 41 al 91. El primer estrato es obra de un único copista (Glossator 1). El copista del segundo estrato (Glossator 2) introdujo las glosas con una letra menor y las colocó debajo de sus lemas en los espacios que habían quedado libres. El primer estrato o glosa principal se caracteriza por una marcada tendencia a la interpretación alegórica, en tanto que el segundo o glosa secundaria es casi exclusivamente literal e histórico. Tales diferencias reflejan la influencia de sus respectivas fuentes; la glosa principal depende sustancialmente de un comentario anónimo del s. VII conocido como Glosa psalmorum ex interpretatione seniorum (AN sen), mientras que la glosa secundaria refleja un tipo de exégesis histórica muy cercana a la que presenta la anónima Glossa in psalmos (AN vat = L\&S BCLL núm. 1261). Aunque las glosas se copiaron poco tiempo después que el texto del salterio, no fueron redactadas para $\mathrm{H}$. Ello lo evidencia el hecho de que, en ocasiones, una glosa comenta un texto del salmo distinto del de $\mathrm{H}$. En el caso de la glosa principal, la dependencia casi exclusiva de una sola fuente confiere unidad al conjunto, una unidad que se manifiesta sobre todo en rasgos de estilo indicativos de un único autor; en este sentido apunta también el uso recurrente de tópicos de carácter interpretativo; entre estos, el más generalizado es la noción de ecclesia primitiua. Aunque en ningún lugar se la define de modo explícito, de las referencias a la misma presentes en veinticinco de las glosas se infiere que tuvo su origen entre los judíos, concretamente en Jerusalén, se cohesionó tras la muerte de Cristo, fue oficialmente sancionada en Pentecostés y luego se propagó entre los gentiles. Una noción similar de ecclesia primitiua aparece también en la Glosa psalmorum (AN sen) y en los comentarios sobre la Biblia de Beda. No obstante, algunas referencias, como la que aparece en la glosa al salmo 92. 2, van más allá: la ecclesia primitiua comienza con Abel y comprende a todos los personajes virtuosos del Antiguo Testamento, en especial, los 
patriarcas y los profetas. Este concepto amplio de ecclesia primitiua, que se extiende desde el Antiguo hasta el Nuevo Testamento, fue elaborado por exegetas de las escuelas irlandeses bastante antes de Beda y así aparece ya en un comentario hiberno-latino sobre las Epístolas Católicas redactado a mediados del s. VII (L\&S BCLL núm. 340). La tendencia a la interpretación alegórica del autor de la glosa, por influencia de su fuente principal, la Glosa psalmorum (AN sen), es un rasgo que lo diferencia claramente del resto de exegetas irlandeses del Salterio, que prefieren enfoques literales o históricos. Entre estos cabe situar al Glossator 2, cuyas interpretaciones literales e históricas podrían ser una reacción contra la tendencia alegórica de la glosa principal. El análisis de las glosas que aparecen al inicio de más de 50 salmos permite establecer un cierto esquema interpretativo. El más común responde a una interpretación triple: histórica (con frecuencia, David), mística (generalmente Cristo o la iglesia primitiva) y moral (el cristiano practicante). Este esquema se observa en 24 salmos, mientras que al menos en otros 30 aparece una versión reducida del mismo en la que se omite la interpretación moral o la mística.

Distribuidas de forma irregular, en $\mathrm{H}$ aparecen unas 52 glosas y términos en lengua irlandesa, de contenido eminentemente léxico, cuya mayor frecuencia se da entre los salmos 51 al 84. De ellas, 29 fueron introducidas por el Glossator 1, otras 20 o 21 lo fueron luego por el Glossator 2, con una minúscula de tamaño menor. La mayoría coincide con el uso del antiguo irlandés clásico, mientras que las pocas desviaciones significativas son compatibles con el antiguo irlandés tardío. Este perfil lingüístico coincide mucho con el de las glosas de Milán y las de Sankt Gallen, lo cual lleva a pensar en una misma datación, es decir, la primera mitad del s. IX.

Como ya se ha dicho, la fuente primera de la glosa principal es el comentario anónimo Glosa psalmorum (AN sen), redactado en la Galia meridional a principios del s. VII para una audiencia monacal. La Glosa gozó de gran predicamento en el continente hasta el s. X, en parte, porque contenía un comentario de la totalidad del Salterio, pero, sobre todo, porque ayudaba a una mejor comprensión del texto que los monjes recitaban a diario en el Oficio Divino. La influencia de este comentario en las glosas de $\mathrm{H}$ es muy marcado. Las diferentes orientaciones interpretativas que la Glosa propone para determinados salmos son las mismas que aparecen en la glosa de $\mathrm{H}$, pero expresadas de forma extremadamente concisa, siguiendo un esquema de tres planos interpretativos en lugar de los cuatro de la Glosa, con un predominio de la interpretación alegórica. Además de la fuente principal, el editor identifica en la glosa de $\mathrm{H}$ la influencia de otros comentarios: a) patrísticos, entre los cuales el de Jerónimo (HI Ps) y, sobre todo, el de Casiodoro (CAr Ps); b) post-patrísticos, en especial, el pseudoJerónimo, Breuiarium in Psalmos (PS-HI Ps $=$ L\&S BCLL núm. 343), redactado en la segunda mitad del s. VII a partir de diversos comentarios, entre ellos, los de Agustín (AG Ps) y Jerónimo; también es de señalar la influencia de los Argumenta (PS-BED Arg) y de las Explanationes sobre los salmos del pseudo-Beda (PS-BED Ps), y c) hiberno-latinos, de estos, parece claro que utilizó un comentario anónimo (AN inc), de procedencia irlandesa y enfoque histórico, redactado en el s. VII, del cual sólo se conserva un fragmento; la glosa principal presenta no menos de 18 correspondencias con este comentario; otra fuente importante, sobre todo, para el Glossator 2, es una obra, hoy perdida, reconstruible en parte gracias a AN vat, que parece transmitir una versión abreviada de la misma. 
El concepto de exégesis bíblica hiberno-latina fue propuesto por Bischoff, a mediados del siglo pasado. Considera este estudioso que un número considerable de comentarios bíblicos medievales tienen un origen irlandés a juzgar por determinadas características de contenido y metodológicas, comunes a todos ellos, que son propias de la tradición exegética bíblica desarrollada por las escuelas irlandesas a partir del s. VII. Esta teoría fue rebatida por Gorman, que considera que no es posible hablar de una tradición exegética bíblica irlandesa dado que cuanto se ha conservado de Irlanda es insignificante en cantidad y en calidad. La argumentación de Gorman en contra de los criterios de Bischoff para la identificación de una obra anónima como irlandesa ha sido contestada por diversos estudiosos. No obstante, la polémica suscitada al respecto ha llevado a una revaluación de tales criterios y a una mayor exigencia de pruebas acreditativas para incluir una obra en el corpus hiberno-latino. En el caso del salterio transmitido por $\mathrm{H}$, el editor ya ha señalado (p. XVII) que este reúne las tres características principales de los salterios irlandeses: 1) un texto de la versión latina gallicana de los salmos, con lecturas propias de la familia irlandesa; 2) una división en tres series de 50 salmos, y 3 ) tres collectae u orationes al final de cada serie, seguidas de los cantica. Cada salmo está dividido en secciones, práctica tomada de la Expositio Psalmorum de Casiodoro, y va encabezado por un titulus, al modo del salterio hebraico. Desde el punto de vista de las pruebas o evidencias externas, el tipo de escritura y la decoración que presenta $\mathrm{H}$, el único ms. que lo transmite, confirman su procedencia de una región gaélica; en el mismo sentido apuntan determinadas formas ortográficas propias de los textos hiberno-latinos. Que el texto no sólo procede de un ámbito irlandés, sino que también tiene su origen en Irlanda lo demuestran determinados rasgos sintácticos explicables por influencia del irlandés antiguo. El autor era alguien no sólo de lengua sino también de formación irlandesa: así lo sugiere la presencia de metodologías, temas y etimologías que aparecen en su mayoría, o incluso de forma exclusiva, en textos hiberno-latinos. Se podría objetar en contra del origen irlandés de la glosa el enfoque predominantemente alegórico de la misma, a diferencia del carácter histórico de la mayoría de exégesis irlandesas del salterio. Para el editor (pp. LXXIV-LXXV), la explicación viene dada por la técnica de redacción de la glosa a partir de las fuentes de que dispone el glosador: por una parte, la versión latina del comentario sobre los salmos de Teodoro de Mopsuetia y el epítome anónimo de ésta, $\mathrm{y}$, por otra, el comentario perdido sobre los salmos que está detrás de AN vat, obras que circularon sólo por Irlanda. El glosador usó estas obras de forma selectiva y siempre en beneficio de interpretaciones alegóricas. El cúmulo de pruebas lingüísticas, de metodología, de temas y de fuentes indica que el autor de la glosa fue alguien que hablaba irlandés y llevó a cabo su tarea en un medio gaélico.

Contrariamente a lo que se había creído, concluye Ó Néill (p. LXXXV), la glosa parece ser una obra unitaria redactada por un solo autor y no un conjunto de glosas tomadas de fuentes diversas. Quizás fue redactada en principio como un comentario continuo del cual se extrajeron secciones y se copiaron en el lugar pertinente del salterio, aunque no siempre el exacto. La redacción de este supuesto comentario se puede situar a mediados del s. IX, época a la que corresponden las palabras en irlandés antiguo que aparecen integradas sintácticamente en el texto latino.

Resulta llamativo el tipo de comentario alegórico que subyace en toda la glosa principal habida cuenta de la tendencia histórica predominante en la exégesis 
irlandesa de los salmos. Quizás el autor pertenecía a una escuela que había primado el enfoque alegórico de los salmos o sencillamente su preferencia por este tipo de comentario se debe a la influencia de su fuente principal, la Glosa Psalmorum (AN sen). Y, en este supuesto, cabe preguntarse por qué el autor prefirió esta fuente. La Glosa es una obra monástica tanto en su origen como en sus destinatarios; se concibió para adecuar los salmos al tipo de vida monástico. Esta orientación monástica, concluye el editor, fue precisamente lo que llevó a un anónimo exegeta irlandés del s. IX a redactar su propio comentario, un comentario que hace hincapié en las interpretaciones alegórica y moral como rasgo que lo diferencia de los comentarios de base histórica usuales entonces en Irlanda.

El estudioso que aborde la consulta del salterio glosado de $\mathrm{H}$ editado por Ó Néill hallará información suficiente y bien argumentada en las más de 70 páginas de la introducción que he intentado sintetizar. En el capítulo segundo del preliminar aparece, en primer lugar, la bibliografía, que el editor dispone en dos apartados: fuentes principales y secundarias; a continuación se detallan las abreviaturas utilizadas en la introducción y en el texto crítico. En el capítulo tercero se da razón de los criterios seguidos en el establecimiento de los diferentes textos que transmite $\mathrm{H}$. El objetivo principal de la edición, se señala (p. XCVII), es presentar un texto de las glosas asequible, con el mínimo de referencias a detalles de su transmisión manuscrita. Para poder valorar las glosas en su contexto original, se ha editado todo el contenido del ms., es decir, los salmos, los tituli bíblicos, los argumenta, las orationes y los canti$c a$. La disposición del texto de los salmos reproduce la que aparece en el ms., con la misma división en secciones y separación de versos. Los argumenta que preceden al salmo, aunque su fuente es la serie del anónimo pseudo-Beda, Argumenta, contienen numerosas lecciones propias que se han mantenido en el texto editado. Al objeto de preservar las características ortográficas y usos sintácticos propios del latín de Irlanda, las correcciones se han reducido a las imprescindibles.

La edición crítica que sigue se acompaña de un triple aparato: en el primero se indican las citas y referencias bíblicas, en el segundo, las fuentes y en el tercero se recogen las notas de índole textual. Cierran el volumen los índices de pasajes bíblicos, de fuentes y un tercero con la relación alfabética de términos del antiguo irlandés que aparecen en $\mathrm{H}$.

LAMBERT FERRERES

Universitat de Barcelona

Pablo OrTego Rico, Poder financiero y gestión tributaria en Castilla: los agentes fiscales en Toledo y su reino (1429-1504), Madrid, Instituto de Estudios Fiscales, 2015, 610 pp.+1 CD. ISBN 978-84-8008-383-6.

Pocos trabajos unen rigor metodológico y fidelidad documental. El libro que reseñamos, Poder financiero y gestión tributaria en Castilla: los agentes fiscales en Toledo y su reino (1429-1504) de Pablo Ortego Rico, es uno de ellos. Fruto de su tesis doctoral, dirigida por M.A. Ladero Quesada y defendida en la Universidad Complutense de Madrid con la calificación de sobresaliente por unanimidad en 2013, 
recoge su tercera parte, que trata el poder financiero y fiscal. Aparece en una de las colecciones que mayor atención ha prestado a la historia de la fiscalidad hispánica durante la última década, la patrocinada por el Instituto de Estudios Fiscales y la red Arca Comunis. Presenta, por tanto, una cuidada edición, acompañada de un CD-ROM que contiene el texto y los apéndices en formato PDF.

Vaya por delante una aclaración y es que el resultado, como advierte el autor, excede su título, convirtiéndose en el mejor análisis para la Castilla bajomedieval de la llamada "vertiente sociológica de la fiscalidad". La obra consta de cinco capítulos, que podemos agrupar en dos bloques. El primero, formado por el primer y segundo capítulo, se dedica a la Real Hacienda durante los reinados de Juan II y Enrique IV desde 1429, en que contamos con las fuentes seriadas del Archivo General de Simancas. Se opta por la presentación de una panorámica general (capítulo 1) a la que sigue lo sucedido en el reino de Toledo (capítulo 2). Esta estructura es abandonada en el segundo de los bloques, integrado por los capítulos tercero, cuarto y quinto, y dedicado al reinado de Isabel I. Existen razones para ello entre las que se encuentra el papel jugado por una serie de conglomerados financieros de fuerte implantación en el área de estudio en el sostenimiento del poder regio (capítulos 3 y 4) y la temprana adopción en algunas de sus zonas de los encabezamientos de rentas (capítulo 5). En uno y otro bloque, y como transición, se sitúan los datos sobre la etapa peor conocida del periodo, que va entre 1464 y 1480 . Su escaso tratamiento anterior hace que las respuestas sean provisionales, si bien se dan claves para su esclarecimiento. Estas se dirigen en tres direcciones: el distanciamiento de los capitales privados del negocio fiscal, las relaciones de simbiosis entre Isabel I y tales agentes y el posterior proceso de control informativo y racionalización del gasto.

El primer capítulo ("El poder financiero...") trata el arrendamiento de la masa, licitación conjunta de las rentas ordinarias del reino por un precio mínimo repartido luego entre las unidades fiscales. Tras su introducción, fechada en 1432 después la llegada de Álvaro de Luna al poder en 1429, este se mantuvo hasta 1465. Clave en dicha supervivencia fue la ductilidad del modelo, que favorecía un mercado dinámico y la estabilidad de la Real Hacienda por encima de coyunturas políticas. Lo primero tiene que ver con la posibilidad de sobrepujar y traspasar unidades de gestión. Lo segundo se relaciona con la estructura piramidal de los agentes fiscales implicados. Esto lleva a interesarse por los grandes financieros del periodo, ya fuesen los arrendadores de la masa o sus fiadores. Sobre los segundos, debemos decir que una de las principales aportaciones del trabajo consiste en su consideración como miembros solidarios de pleno derecho de las compañías a las que avalaban. Consecuencia de esto es una amplia nómina de agentes fiscales durante la etapa, procediendo muchos, como Juan Ramírez de Toledo, del área de estudio pero existiendo elementos, Abrahem Bienveniste por ejemplo, ajenos a esta. La atención no es meramente prosopográfica y aspectos como el entorno denso de los financieros y sus relaciones informales son objeto de estudio. Así, la metodología del análisis de redes sociales es empleada con notable acierto. Dicho análisis observa la importancia de los diferentes actores de un contexto determinado a la luz de su espectro relacional amplio. Conceptos como "índice de intermediación" y "rango normalizado" son instrumentos para comprender la naturaleza de los vínculos establecidos entre los diferentes agentes y su relación con la Real Hacienda. 
Todo ello permite abordar la realidad regional en el segundo capítulo (“Arrendadores y financieros..."). Este trata el arrendamiento de la masa en los partidos fiscales de Guadalajara, Talavera de la Reina y Toledo. A los aspectos que facilitaban la funcionalidad del sistema se suma una fecunda interacción con los grupos que, interesados en sus núcleos urbanos, no proyectaron sus actividades fiscales a toda la Corona. Se abre así un amplio abanico de casuísticas particulares que, en Guadalajara, está marcado por la presencia del clan mendocino. Talavera de la Reina nos muestra, al contrario, como el control de un mismo partido fiscal por unos actores determinados durante un periodo de tiempo prolongado, los González de San Martín y García de la Rúa entre 1439 y 1465, puede posibilitar la extensión de sus negocios a zonas limítrofes de mayor entidad. Toledo, en cambio, fue el gran centro del negocio fiscal en Castilla la Nueva hasta la segunda mitad del reinado de los Reyes Católicos. No es de extrañar, por tanto, la atención a la misma, que se caracteriza de acuerdo a la concurrencia de tres grupos: una élite del común integrada por familias de jurados y mercaderes de origen judeoconverso en muchos casos, una presencia de elementos burocráticos y cortesanos y una pervivencia de la gestión fiscal por parte de judíos. La unidad de los mismos es expresada nuevamente mediante el análisis de redes sociales, que permite su adecuada jerarquización.

El tercer ("Compañías y financieros...") y el cuarto capítulo ("Culminación y ocaso...") se centran en el grupo financiero de Luis de Alcalá, Abrahem Seneor, Abrahem Bienveniste y Rabí Mayr. El rastreo de las actividades de algunos de sus miembros, Luis de Alcalá sobre todo, en tiempos de Enrique IV prueba su vinculación al poder regio antes del reinado de Isabel I. Se abría entonces un periodo de guerra civil en el que se dan tres tendencias: la continuidad de los problemas recaudatorios, el riesgo de quienes apoyaron a los soberanos mediante adelantos de capital y los beneficios con que este quedó justificado tras su consolidación en el trono. No se dibuja, con ello, un panorama finalista, pues se presta atención a las composiciones de la compañía durante estos años así como a la participación de otros grupos en la recaudación. Las nuevas necesidades de gestión hacendística a partir de 1480 llevaron a su transformación en un oligopolio financiero y a una mayor acritud en sus luchas con otros elementos. Este conjunto de cambios tuvo su cenit en la receptoría y pagaduría general del reino, con que los reyes invistieron a Luis de Alcalá y Rabí Mayr en 1491. Se les concedía la gestión de la práctica totalidad de pagos mediante libranza aunque sin tener igual condición sobre la recaudación, que siguió rigiéndose mediante pujas conjuntas a gran parte de los partidos del reino y en las que la oposición del grupo financiero de Almagro controlado por Fernando de Villarreal y Alonso Gutiérrez de Madrid fue cada vez mayor. Desde entonces, los problemas serían una constante entre ambas compañías estando estimulados por la concesión de prometidos crecientes. Las acusaciones a los receptores se hicieron realidad a raíz de la expulsión de los judíos, que socavó las bases de su crédito, culminando con su quiebra y liquidación.

El quinto capítulo ("Los inicios...") analiza las consecuencias de la introducción en 1495 de los encabezamientos de rentas. Este suponía la entrega a la Real Hacienda, por parte de una comunidad, de un tanto alzado a cambio de hacerse con el control de la gestión recaudatoria en su jurisdicción, lo que incluía el reparto por menor. El interés no radica tanto en los detalles de la adopción del nuevo método o en su plasmación en Castilla la Nueva, que el autor describe en el mejor relato de los 
mismos, como en su relación con las crecientes necesidades crediticias. Los encabezamientos de rentas favorecieron la obligación a guardas y los juros al quitar, algo evidente si tenemos en cuenta su papel como punto de llegada y partida de buena parte de los cambios hacendísticos entre los siglos XV y XVI. Menos lo es que tales elementos formasen parte de una estrategia conjunta esbozada en las Cortes de Toledo de 1480 como se ha defendido recientemente. Junto a esto, se produce un nuevo uso del viejo sistema de receptorías, encargos a individuos para el cobro de cantidades, el finca por lo general, en un área fiscal. Al respecto, se estudia su empleo para el reembolso de los montos adelantados por los financieros en la obligación a guardas, lo que conllevó una actualización de la geografía fiscal.

M.A. Ladero Quesada valoraba, recientemente, la relación entre "lo viejo y lo nuevo" en el estudio del fisco castellano bajomedieval, aludiendo al continuismo de las investigaciones entre 1973 y nuestros días. El trabajo que reseñamos se presenta como el más firme desafío a dicha afirmación. A P. Ortego Rico corresponde el haber introducido los conceptos de capital social y relacional en la comprensión de la Real Hacienda de Castilla entre 1429 y 1504, toda vez que su análisis de apartados como los grupos financieros, el papel de los fiadores en ellos o las relaciones de estos con el poder cortesano quedarán como ejemplo. El resultado es una obra de enorme precisión conceptual y teórica, dando lugar a un relato dinámico y carente de encorsetamientos. Lo nuevo, pues, ha llegado.

FEDERICO GÁLVEZ GAMBERO Universidad de Málaga

Rodrigue Tréton (ed.), Diplomatari del Masdéu, Barcelona, Fundació Noguera, 2010, 3211 pp. (Col·lecció Diplomataris; 52, 53, 54, 55, 56). ISBN 978-849779-967-5.

És ben sabut que les terres del Rosselló i la Catalunya nord en general, no comparteixen la proverbial riquesa dels arxius dels comtats catalans de l'Edat Mitjana central. En aquest context, la comanda templera del Masdéu, prop de Perpinyà, forneix a l'investigador el fons documental més important avui conservat tant per la qualitat com per la quantitat de les actes preservades -molt superior al de la catedral d'Elna, per exemple, o al de les grans abadies de St. Miquel de Cuixà i Sta. Maria d'Arles-. El cartulari, que aplega una bona part dels documents de la comanda, és l'únic medieval conservat d'una institució de la diòcesi. Aquesta peça clau per al coneixement de la història del Rosselló ja havia estat la base de diverses monografies i treballs especialitzats, especialment els de L. Verdon (La terre et les hommes en Roussillon aux XIIe et XIIIe siècles, 2001) i R. Vinas (Els templers al Rosselló, 2002). En aquesta obra, en cinc volums, per fi se'ns ofereix una edició de tota la documentació d'aquesta comanda templera. El treball és el resultat d'una tesi doctoral llegida a la Universitat de París I (Panthéon-Sorbonne) l'any 2007, dirigida per Olivier Guyotjeannin, un reputat especialista en diplomàtica i tota una garantia per a la qualitat de l'edició.

El Diplomatari ve precedit d'una llarga introducció dedicada a la història dels templers al Rosselló, que comença amb una primerenca donació a l'orde de l'any 
1128 (doc. 175), abans de la vinguda de Robert de Craon, primer senescal del Temple, i Hug Rigald, l'any 1131, a la que succeeix una primera menció, en un testament del 1136, de la domus Templi Mansi Dei, fundada en un alou situat a Cirà, cosa que la converteix en la més antiga de les cases del Temple en terres catalanes, i una de les més antigues d'Occident. També molt aviat s'hi documenta una capella -amb uns frares capellans-, lligada a un cementiri on demanen ser enterrats molts dels benefactors de la comanda.

L'autor ressegueix els integrants de la comunitat, siguin aquests frares cavallers, procedents sempre de famílies aristocràtiques, capellans o clergues que asseguraven els oficis litúrgics, frares sergents sovint de les famílies pageses del domini, i un conjunt de confrares (fratres ad succurrendum) o laics donats en múltiples variants, que en general demanen ser enterrats al cementiri de la comanda. Entre aquests darrers hi havia Pèire, vescomte de Fenolleda, condemnat per heretge càtar l'any 1263 , després de la seva mort. Al costat d'aquests confrares nobles hi havia simples oblats o laics que es lliuraven a l'establiment per obtenir-ne beneficis espirituals però també una protecció i empara en situacions que voregen la dels homes propis i solius, tal com ja havia detectat Paul Freedman. Entre aquests grups hi havia un nombre significatiu de dones, algunes de les quals aportaren donacions importants per al patrimoni del Temple.

Des de ben aviat, la comanda del Masdéu va enriquir el seu patrimoni amb donacions dels seus benefactors, sovint estimulades per les compensacions pecuniàries que oferien els templers com a "almoina" i qualificades per l'autor de vendes camuflades. Els importants recursos esmerçats permeteren als templers quedar-se amb les senyories d'Orla i l'antic priorat de St. Salvador de Cirà, a la segona meitat del segle XIII, en època de l'ambiciós comanador Ramon Desbac. I ja abans sorgiren cases secundàries, com la del Mas de la Garriga, que responen a una important expansió territorial que es plasma en un apèndix cartogràfic esplèndid.

Pel que fa al domini, l'estudi de Rodrigue Tréton es centra en dos aspectes: la dedicació ramadera i les inversions urbanes a la vila de Perpinyà. En relació al primer, demostra molt bé els lligams entre aquesta activitat i algunes importants inversions, com per exemple la dessecació dels estanys de la plana; mentre la llana dels ramats dels templers responia a la demanda d'una manufactura drapera en plena expansió. El segon centre d'interès privilegiat per l'autor és, precisament, la relació entre els templers amb la vila de Perpinyà, on des del 1139 tenien terres i altres béns immobles, entre els quals destaquen ben aviat els molins situats als afores del nucli urbà. Abans de la fi del segle XII, els templers també tenien les mesures del mercat, taules al mercat de l'oli, i els forns, gràcies a la cada cop més estreta relació amb els comtes i després el reis. A mitjan segle XIII també es constata l'interès dels templers pel sector de la manufactura amb la construcció d'una blanqueria, però també la possessió d'obradors a la parairia o encara una teuleria, en un context d'expansió del teixit urbà. Els templers van tenir un paper protagonista en la urbanització de nous barris a Perpinyà, com el de St. Francesc, a través de la parcel·lació i concessió, a través d'establiments, d'espais per a construir-hi cases. Els contractes emfitèutics d'aquesta mena es compten per centenars en les dècades centrals del segle XIII.

Els templers també van tenir un paper molt destacat al servei de la Corona. La seva experiència en la gestió, els seus recursos i la seva participació en els negocis 
urbans expliquen la confiança que els atorga el rei de Mallorca, el tresor del qual es custodiava a la casa del temple de Perpinyà. Els darrers comanadors de la casa de Perpinyà, fra Pere de Camprodon i fra Jaume d'Ollers, van ser també procuradors del rei, és a dir, els encarregats de tenir cura del patrimoni reial, arran de la creació de la procuració reial l'any 1258. Al segon es deu, en col·laboració amb el jurista Guillem de Capellades, la recopilació de reconeixements o capbreu del domini reial dels anys 1292-94, on es veuen unes imatges del templer, excepcionals per ser coetànies, i de les quals se n'adjunta una mostra en l'apèndix.

L'estudi introductori s'acaba amb la supressió de l'orde del Temple i l'arrest dels frares l'any 1307. Els templers del Masdéu van ser declarats innocents en el procés subsegüent i la documentació aplegada permet resseguir la biografia d'alguns dels frares un cop dissolta la comunitat, que s'allarga fins l'any 1350 en el cas de fra Berenguer Descoll, quan el patrimoni havia sigut ja encomanat a l'orde de l'Hospital.

Una segona part del volum introductori consisteix en una molt detallada presentació del conjunt de documents. El fons de l'antiga comanda del Masdéu comprèn uns 300 documents, des del 1001 fins al 1307, i un cartulari, anomenat Llibre de la Creu, guardats a l'Arxiu Departamental dels Pirineus Orientals. La majoria dels documents són pergamins originals tot i que també s'han inclòs en el recull algunes còpies modernes. Com ja és habitual, el fons inclou munimia és a dir transmissions prèvies de béns que acabarien al domini del Temple, i això explica, per exemple, el primer document del Diplomatari, del 1001, que és una adquisició feta pel comte Bernat I de Besalú.

Rodrigue Tréton descriu amb una precisió admirable el cartulari del Llibre de la Creu que conté no menys de 866 documents en 481 folis, quasi tots d'una sola mà de finals del segle XIII, i que s'atribueixen a algun dels escrivans de la notaria d'Arnau Miró. Seguint la petja dels magnífics treballs de Pierre Chastang sobre els cartularis llenguadocians, l'autor en ressegueix l'estructura interna i fa notar el predomini dels documents que es refereixen a Perpinyà i al territori adjacent. Tal com succeeix entre els documents en pergamí, el cartulari conté sobretot vendes i donacions amb les quals es va constituir el patrimoni i un gran nombre d'establiments (416 en el cartulari!), qualificats d' acaptes, seguint la terminologia llenguadociana. Rodrigue Tréton reconstrueix amb molta cura el context que va envoltar la decisió de fer el cartulari, vers el 1282, un cop ja havia acabat l'onada principal d'establiments per a la construcció de cases a Perpinyà. Aquest fou un moment àlgid de la casa templera que, sota la direcció del procurador reial fra Pere de Camprodon, es va renovar i ampliar amb la construcció de l'església de Sta. Maria, esmentada per primer cop el 1277, però també va ser un moment crucial per a la ciutat que s'havia convertit en capital d'un regne.

Als documents del fons de la comanda del Masdéu, R. Tréton hi ha afegit fins a 96 documents més, peces complementàries, col-locades al final del diplomatari amb una altra numeració. En concret són 30 notes dels protocols notarials dels anys 1260 al 1286, on es troben notícies d'activitats econòmiques en les quals els templers estaven més o menys directament implicats; també inclou 10 documents del fons de la procuració reial i una petita selecció de documents del fons del Gran Priorat de Catalunya, de l'Arxiu de la Corona d'Aragó. Finalment, inclou també un capbreu o inventari del 1264, conservat a l'Arxiu de Montserrat, que havia estat publicat per 
Cebrià Baraut i que resulta extraordinàriament útil per al coneixement del patrimoni (doc. XXIX).

La introducció també s'ocupa de les vivències del fons arxivístic del Masdéu, que l'any 1258 ja era custodiat a la casa del Temple a Perpinyà i on es va preservar fins i tot després que la comanda quedés sota el control de l'orde dels Hospitalers (1313). Els inventaris d'època moderna, especialment un del 1792, demostren l'abast de les pèrdues subsegüents: en particular quasi dos centenars de capbreus i centenars de lligalls de pergamins, en total uns 3.500 documents que van ser numerats a principis del segle XVIII i dels quals ara només en resta una petita mostra. L'autor constata que el $90 \%$ de la documentació es devia perdre durant la Revolució francesa. Són les restes d'aquest fons malmès les que va començar a donar a conèixer J.B. Alart, director de l'Arxiu Departamental a la segona meitat del segle XIX, i també, André d'Albon que en va fer còpies per a la publicació del seu Cartulaire general de l'ordre du Temple (París, 1913).

Aquest diplomatari és, doncs, una edició modèlica, tan per la cura amb què s'han realitzat les transcripcions, amb uns generosos regests i uns índexs exhaustius, com per l'excel-lent treball introductori que demostra el rigor amb el qual s'ha analitzat i contextualitzat el corpus documental. Els historiadors interessats en la història dels templers i en la de Perpinyà i el Rosselló durant els segles centrals de l'Edat Mitjana, compten amb una obra d'un interès excepcional.

LLUís TO FIGUERAS Universitat de Girona

Pau Viciano, Els peus que calciguen la terra. Els llauradors del País Valencià a la fi de l'edat mitjana, València, Universitat de València, 2012, 265 pp. ISBN 978-84-370-8870-9.

Aquesta obra de Pau Viciano utilitza com a fil conductor la història dels llauradors, un terme que, malgrat una certa polisèmia, es reservava als camperols cristians en el País Valencià medieval. Precisament el primer capítol del llibre, dedicat a repassar la nomenclatura utilitzada en les fonts escrites per designar els camperols i les seves jerarquies o divisions internes, constitueix una de les contribucions més originals del llibre. Una altra és la utilització de les dades d'una relació de focs del 1510 que serveix per fer estimacions sobre els efectius de la població pagesa (38.000 focs, un $68 \%$ de la població), les proporcions de cristians i musulmans, la seva adscripció a les terres del rei, noblesa i Església, o encara la grandària dels nuclis de poblament on vivien (els únics quadres del llibre resumeixen les dades extretes d'aquest cens de 1510, pp. 243-245). Això permet constatar un dels trets característics dels llauradors valencians com és el fet de viure, en bona part, en viles i ciutats.

El llibre és una síntesi que aprofita els nombrosos estudis i monografies realitzats pels medievalistes valencians en els darrers decennis -entre els quals cal comptar el mateix Pau Viciano. El seu principal valor consisteix en presentar amb relativa brevetat els grans temes d'una història rural clàssica: el procés de formació i reproducció dels grups domèstics, l'accés a la terra i les desigualtats socials, la 
producció i el treball, la renda senyorial i els mercats, i els diversos marcs comunitaris com la senyoria o el municipi.

Alguns capítols són especialment il·lustratius i eloqüents. En el cinquè, per exemple, s'expliquen els mecanismes familiars que permetien transmetre les heretats i com aquests es complementaven amb un mercat de la terra i un mercat d'arrendaments que permetia als joves accedir, gradualment, a la possessió d'una explotació agrària. També es mostra com el treball assalariat de jornalers i mossos es convertia en un suplement per als qui no tenien prou recursos o per a aquells que es trobaven en els inicis de la seva vida laboral. El capítol dedicat a la petita explotació, que també demostra l'alt nivell assolit pels estudis especialitzats, analitza els tipus de conreus -amb unes pautes diferenciades per als musulmans-, els animals, les eines i els rendiments per superfície que resultaven particularment alts allí on s'utilitzava la irrigació.

Un dels eixos del llibre és la contraposició entre camperols musulmans i llauradors cristians que substitueix la vella i obsoleta dicotomia entre camperols de reialenc i de la noblesa. Els musulmans, conceptualitzats com a serfs, tot i ser una minoria, aportaven una part essencial de la renda senyorial, vivien en bona part en aljames situades a l'interior del regne, i sovint quedaven relegats a la condició de mitgers o jornalers, sense drets a la terra (eixarics o examesos). Les càrregues i serveis en treball que pesaven sobre els musulmans eren indubtablement més durs que els que s'exigien als cristians, però també són destacables les intromissions senyorials en la transmissió hereditària de les seves heretats. La renda era molt més lleugera per als llauradors cristians, però Pau Viciano adverteix que caldria afegir-hi la fiscalitat provocada per les demandes reials i els costos de l'endeutament de llarga durada (censals i violaris). El resultat era una subordinació col·lectiva de la pagesia en la societat feudal del regne de València.

També s'analitza el paper dels mercats, en totes les seves vessants, tot i que Pau Viciano remarca els límits de la comercialització: els llauradors amb una possessió estable de la terra podien assegurar una bona part del consum familiar amb la producció domèstica i això reduïa la seva dependència dels mercats. En general, segons el seu punt de vista, els llauradors acudien als mercats més per a vendre i obtenir moneda per a pagar rendes, deutes $i$ impostos que no per a consumir (p. 183), tot $\mathrm{i}$ que més endavant anota la necessitat, per a molts, de comprar periòdicament animals d'arada i eines. Per a la societat rural es subratllen els efectes "jerarquitzadors" dels mercats dels cereals, dels animals o del crèdit. Si els llauradors pobres es veien obligats a vendre la producció agrícola en les pitjors condicions, els rics o els burgesos i mercaders podien aprofitar-se de les necessitats dels seus veïns per especular. I també en relació al crèdit es produiia el mateix efecte: els llauradors pobres es veien forçats a endeutar-se mentre d'altres s'aprofitaven de les seves necessitats pecuniàries.

Una atenció particular es dedica al mercat de la terra -de parcel·les aïlladesque tot i tenir una funció reguladora per compensar les disgregacions, també permetia a uns pocs llauradors rics treure profit de les penúries dels altres i arrodonir les seves heretats. Això explicaria les importants desigualtats en les dimensions de les explotacions agràries i en les fortunes dels llauradors. D'aquí també l'existència d'una petita minoria de llauradors rics ("kulaks" segons la terminologia emprada per l'autor) contraposada a una majoria de llauradors amb poca terra (per sota de les $5 \mathrm{ha}$ ), amb algunes situacions intermèdies. Però si aquestes desigualtats tenen els seus paral·lelismes 
en altres llocs de l'Occident europeu, P. Viciano afegeix matisos importants per al cas valencià. L'acumulació de terres tenia els seus límits i els llauradors enriquits no arribaven a convertir-se en empresaris grangers: en tot cas, invertien en altres sectors i eventualment deixaven de ser llauradors. Tampoc els empobrits acabaven formant un proletariat rural estable de bracers i jornalers. Per tant, les desigualtats no es van consolidar fins al punt de provocar una escissió en el grup social dels camperols, al marge de la ja existent entre cristians i musulmans.

El llibre se centra més en els aspectes estructurals i menys en els canvis al llarg del temps. Fruit del biaix existent en les recerques publicades i segurament, també, en les fonts conservades, es presenten més exemples referents al segle XV o principis del XVI que no de les centúries anteriors. La manca de profunditat cronològica es fa evident en alguns casos on s'agrairia un major detall de l'evolució temporal si les fonts ho permetessin. Per exemple, costa entendre com una forta contracció demogràfica -amb un baixíssim nombre de fills supervivents per parella-és compatible amb una dramàtica insuficiència de la superfície de les heretats familiars. En canvi, es descriuen molt bé els canvis que suposa la introducció de nous cultius com l'arròs, la canyamel i la morera, o la substitució dels bous per èquids com a força motriu als camps, amb totes les seves implicacions socials.

El llibre acaba amb una anàlisi dels indicis de lluites socials que oposaven els camperols als detentors de la senyoria. Unes tensions que, tot i no traduir-se en revoltes obertes abans de les Germanies, van propiciar canvis, entre d'altres, en el nivell de les rendes exigides. El resultat, un cop més, variava segons si es tractava de cristians o musulmans. En definitiva l'obra no presenta grans novetats en relació a l'estat dels coneixements, però sí constitueix una valuosa síntesi particularment útil per obtenir una visió de conjunt dels assoliments d'una historiografia valenciana que en els darrers anys ha estat particularment fecunda.

LLUÍs TO FIGUERAS Universitat de Girona 